\title{
Anisotropic structure beneath central Java from local earthquake tomography
}

\author{
Ivan Koulakov \\ Institute of Petroleum Geology and Geophysics, SB RAS, Prospekt Akademika Koptuga, 3, Novosibirsk, 630090, Russia \\ GeoForschungsZentrum Potsdam, Telegrafenberg, D-14473 Potsdam, Germany (koulakoviy@ipgg.nsc.ru)
}

\begin{abstract}
Andrey Jakovlev
Institut für Geowissenschaften Facheinheit Geophysik, Johann Wolfgang Goethe-Universität, Feldbergstrasse 47, D-60323 Frankfurt am Main, Germany
\end{abstract}

Institute of Petroleum Geology and Geophysics, SB RAS, Prospekt Akademika Koptuga, 3, Novosibirsk, 630090, Russia

\author{
Birger G. Luehr \\ GeoForschungsZentrum Potsdam, Telegrafenberg, D-14473 Potsdam, Germany
}

[1] In this study we present the new tomographic code ANITA which provides 3-D anisotropic $P$ and isotropic $S$ velocity distribution based on $P$ and $S$ traveltimes from local seismicity. For the $P$ anisotropic model, we determine four parameters for each parameterization cell. This represents an orthorhombic anisotropy with one predefined direction oriented vertically. Three of the parameters describe slowness variations along three horizontal orientations with azimuths of $0^{\circ}, 60^{\circ}$, and $120^{\circ}$, and one is a perturbation along the vertical axis. The nonlinear iterative inversion procedure is similar to that used in the LOTOS code. We have implemented this algorithm for the updated data set of central Java, part of which was previously used for the isotropic inversion. It was obtained that the crustal and uppermost mantle velocity structure beneath central Java is strongly anisotropic with $7-10 \%$ of maximal difference between slow and fast velocity in different directions. In the forearc (area between southern coast and volcanoes), the structure of both isotropic and anisotropic structure is strongly heterogeneous. Variety of anisotropy orientations and highly contrasted velocity patterns can be explained by a complex block structure of the crust. Beneath volcanoes we observe faster velocities in vertical direction, which is probably an indicator for vertically oriented structures (channels, dykes). In the crust beneath the middle part of central Java, north to Merapi and Lawu volcanoes, we observe a large and very intense anomaly with a velocity decrease of up to $30 \%$ and $35 \%$ for $P$ and $S$ models, respectively. Inside this anomaly E-W orientation of fast velocity takes place, probably caused by regional extension stress regime. In a vertical section we observe faster horizontal velocities inside this anomaly that might be explained by layering of sediments and/or penetration of quasi-horizontal lenses with molten magma. In the mantle, trench parallel anisotropy is observed throughout the study area. Such anisotropy in the slab entrained corner flow may be due to presence of B-type olivine having predominant axis parallel to the shear direction, which appears in conditions of high water or/and melting content.

Components: 14,223 words, 18 figures, 4 tables.

Keywords: anisotropy; local earthquake tomography; central Java; Merapi. 
Index Terms: 7270 Seismology: Tomography (6982, 8180); 7240 Seismology: Subduction zones (1207, 1219, 1240); 7280 Seismology: Volcano seismology (8419).

Received 26 May 2008; Revised 10 December 2008; Accepted 6 January 2009; Published 24 February 2009.

Koulakov, I., A. Jakovlev, and B. G. Luehr (2009), Anisotropic structure beneath central Java from local earthquake tomography, Geochem. Geophys. Geosyst., 10, Q02011, doi:10.1029/2008GC002109.

\section{Introduction}

[2] Central Java, being one of the most densely populated areas in the world, suffers high risk of volcanic eruptions, earthquakes, tsunamis, and other natural catastrophes. Understanding their nature and their link with deep processes is a very important task in geosciences. Seismic tomography is one of the most effective tools for investigating the structure of the crust and underlying mantle. It provides the keys for understanding the links between deep processes and surface tectonics.

[3] This study continues our previous research on investigating the deep structure beneath central Java using the local earthquake tomography method. In the work of Koulakov et al. [2007] we have performed a tomographic inversion using arrival times from local events recorded by more than 130 seismic stations in the framework of the MERAMEX project. In that paper we have presented the local tomography algorithm, LOTOS-06, which was applied for processing this data set. Special attention was paid to checking the reliability of the obtained results using many different tests. The most important result was an extremely strong anomaly in the crust, located north of the main volcanic complexes (Sumbing, Merapi, and Lawu), which was named the Merapi-Lawu anomaly (MLA). This anomaly is $\sim 30 \mathrm{~km}$ wide and $\sim 80 \mathrm{~km}$ long and has maximum perturbation amplitudes of $30 \%$ for $P$ and $35 \%$ for $S$ velocity. In a study by Wagner et al. [2007], this data set was complemented with traveltimes from artificial sources, produced by air guns along three profiles off central Java, in the Indian Ocean. These shots were recorded by the same stations as the natural sources, therefore allowing successful combination of both data sets. As a result, the resolution was significantly improved for the uppermost $15 \mathrm{~km}$ beneath the forearc and some offshore parts.

[4] A very important problem has been singled out in these previous studies: in spite of the relatively high pick quality (especially for $P$ traveltimes), the level of remnant residuals was relatively high
( $0.30 \mathrm{~s}$ for $P$ and $0.50 \mathrm{~s}$ for $S$ data). In the present study we have opted for stricter data selection criteria, and for the isotropic model we have achieved $0.23 \mathrm{~s}$ for $P$ and $0.35 \mathrm{~s}$ for $S$ residuals, but these values remain higher than the estimated picking error. We suggested two possible explanations for this fact. First, these remnant residuals could be due to inclusions of relatively small $(1-10 \mathrm{~km}$ size $)$ pockets of contrasted material, which cannot be resolved by the tomography method, but might affect the traveltimes. This would produce the noise contained in the remnant residuals after inversion.

[5] The other hypothesis states that these unexplained residuals might be related to anisotropy, which was not taken into account by the LOTOS-06 algorithm. In the tectonically active area of central Java, existence of fairly strong anisotropy is probable. In the framework of this study we have developed an algorithm for anisotropic local tomography (ANITA) and applied it to the updated data set of central Java.

[6] The main purpose of this study is to present an anisotropic model for central Java, obtained using the ANITA algorithm which significantly improves the data fit. The information about anisotropic properties provided by this study allows us to draw some important geodynamical conclusions.

\section{Data Description}

[7] In this study we use information about the local seismicity of central Java which was collected by a temporary seismological network installed in the framework of the MERAMEX project. The network consisted of 134 continuously recording seismic stations covering a region of about $150 \times$ $200 \mathrm{~km}$ (Figure 1). The stations were in operation for about 150 days from May to October 2004. All the arrival times were picked manually. More details about recording conditions, instruments and distribution of events are provided by Koulakov et al. [2007]. Since the previous study, the total amount of processed events has increased from 292 to 505. However, in the present work we used stricter 


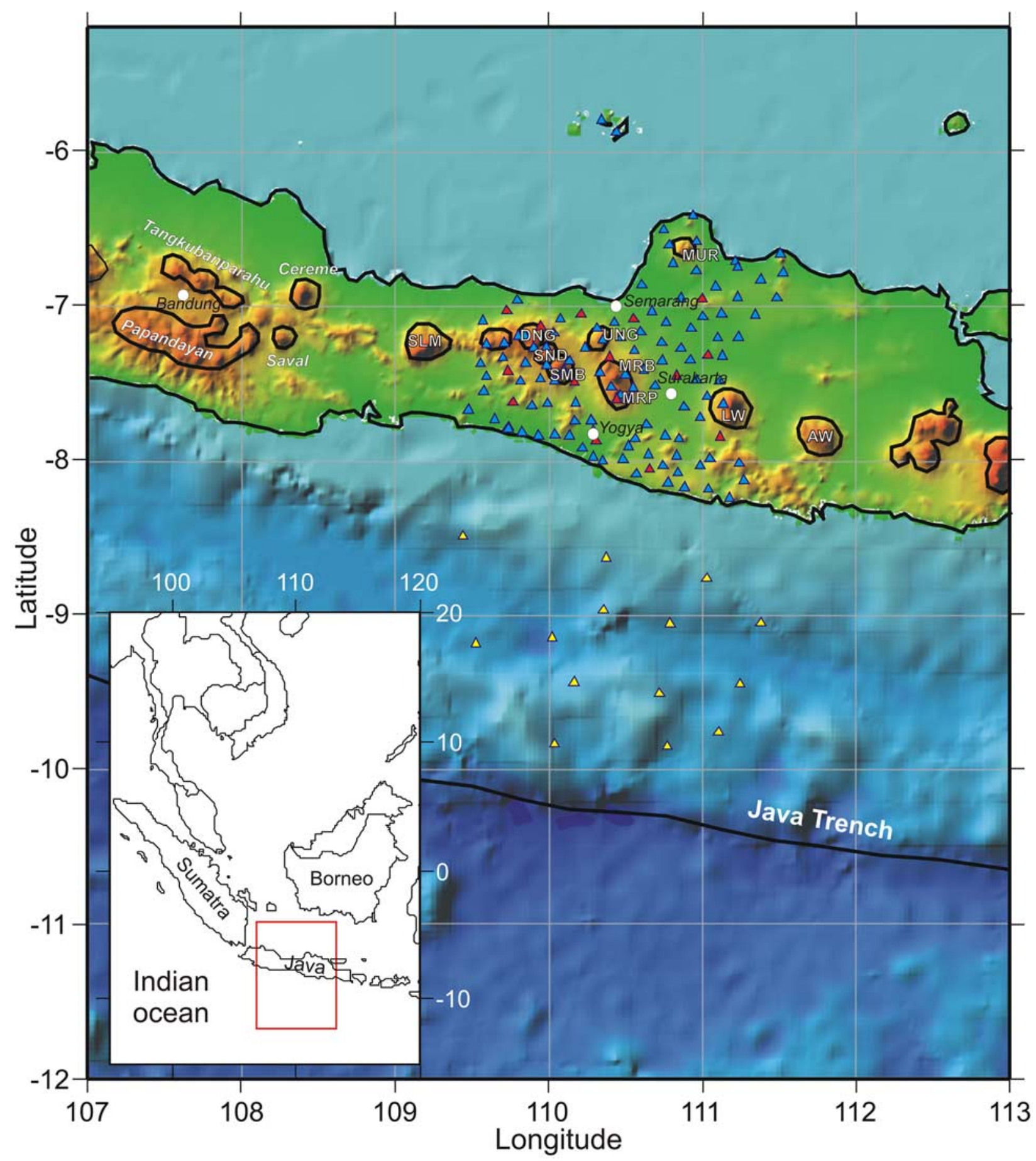

Figure 1. Relief and bathymetry of the study area. The main volcanic complexes are highlighted with black contour lines. Volcanoes are abbreviated as follows: SLM, Slamet; DNG, Dieng; SND, Sundoro; SMB, Sumbing; MRB, Merbabu; MRP, Merapi; MUR, Muria; LW, Lawu; AW, Arjuno-Welirang. The main cities are marked with white circles. Triangles show positions of the MERAMEX stations (red indicates broadband stations, blue indicates shortperiod stations, and yellow indicates ocean bottom stations).

criteria for data selection and therefore only 344 events were used for the final inversion. In this study, the maximum distance from an event to the nearest station is less than $150 \mathrm{~km}$ (no limit in the previous study), the numbers of picks for each event is more than 20 (10 in the previous study), and the maximum residual is $2 \mathrm{~s}$ (4 $\mathrm{s}$ in the previous study). In total, 15,500 phases (9424 $P$ 
and $6076 S$ phases) were selected for simultaneous iterative source location and tomographic inversion.

[8] We do not use the GAP criterion, presuming locating the sources merely inside the network perimeter, which is used in many tomographic studies. In our opinion, the GAP criterion is not useful for data selection, and even injurious as rejecting a lot of relevant information which could improve the resolution of the model.

[9] Final event locations, after five iterative inversion steps, are shown in Figure 2, in map view and projected onto a vertical profile parallel to the subduction direction. For the first $150 \mathrm{~km}$ from the trench $(50-200 \mathrm{~km}$ in Figures $2 \mathrm{a}$ and $2 \mathrm{~b})$ the observed amount of events was relatively low. Most of the seismicity is located beneath the offshore and forearc. From the vertical section it can be seen that the events line up along the Benioff zone in a $30-40 \mathrm{~km}$ thick layer. They clearly image variable dipping angle of the slab. For the first $150 \mathrm{~km}$, from the trench, the slab appears to be almost horizontal. For the next $200 \mathrm{~km}$ distance (between $\mathrm{km} 250$ and 450 in Figures 2a and $2 \mathrm{~b}$ ), the dipping angle of the slab increases to about $45^{\circ}$. For the depth interval from 250 to $600 \mathrm{~km}$ the shape of the slab was estimated using the deep events ( $\sim 600 \mathrm{~km}$ depth) from the worldwide catalog (ISC). In this segment the slab dips rather steeply with $\sim 70^{\circ}$. Another feature that arises from the seismicity distribution is the existence of a double seismic zone in the depth interval between 40 and $130 \mathrm{~km}$, with width of $30-40 \mathrm{~km}$ and a dipping angle of about $45^{\circ}$.

[10] The MERAMEX event catalog has not yet been completed so in the near future a considerable volume of additional events are expected to be available in order to improve the models.

\section{Algorithm for Anisotropic Local Tomography Inversion}

[11] Algorithms for anisotropic seismic tomography are being developed since the 1960s [Backus, 1965]. There are several different approaches which are used for investigating the anisotropic structure of the Earth. Most of them are listed in an overview by Fouch and Rondenay [2006] which includes shear wave splitting, receiver functions, $P n$ anisotropy, and body wave teleseismic and local earthquake tomography. Shear wave splitting of local and teleseismic earthquake data is the most popular method for anisotropy studies. Initially this method has been created for obtaining integral anisotropy values of beneath individual stations [e.g., Kind et al., 1985; Vinnik et al., 1989]. However, during the last years several studies on 3-D tomographic inversion of splitting data have appeared [e.g., Abt and Fischer, 2008; Long et al., 2008]. Approaches based on using the $P n$ waves are oriented on studying 2-D anisotropy beneath the Moho, using two horizontally oriented symmetry axes [e.g., Hearn, 1996; Song et al., 2004; Liang et al., 2004; Serrano et al., 2005]. In these studies, only lateral segments of $P n$ waves below the Moho were used. There are several approaches on deriving 3-D anisotropic properties based on traveltimes of body waves; however they are less extensively used as previously mentioned approaches. Residual times of telesesmic $P$ waves were used in the work of Bokelmann [2002] to derive six coefficients which describe 3-D distribution of anisotropy. Another example is a study by Hammond and Toomey [2003] where an anisotropic structure beneath East Pacific Rise was obtained based on teleseismic traveltimes. The case with 3-D distribution of raypaths in local earthquake tomography was considered in the work of Eberhart-Phillips and Henderson [2004]. In addition to two horizontal parameters they included another parameter related to the vertical velocity perturbation. A similar formalism has been applied in the work of Ishise and Oda [2005] to study the $3-\mathrm{D}$ anisotropic $P$ velocity structure beneath northern Japan. In the present work we follow the same general idea as described in the later two studies. However, in our algorithm we use a significantly different representation of the anisotropy ellipsoid. In addition, we apply another parameterization method and an iterative nonlinear inversion strategy which includes ray tracing in 3-D anisotropic media. Simultaneous developing both approaches based on $S$ data splitting and traveltimes of body waves is important. First, they are mostly oriented on different types of waves, $S$ and $P$, and their joint consideration provides additional information for interpretation. Second, the problem of $S$ splitting is poor vertical resolution, while the problem of traveltime approaches is tradeoff between isotropic and anisotropic parameters. Combining these two approaches will help to partly overcome both problems.

[12] Here we present the Anisitropic Tomography Algorithm (ANITA) for iterative nonlinear inversion of local earthquake data in orthorhombic 

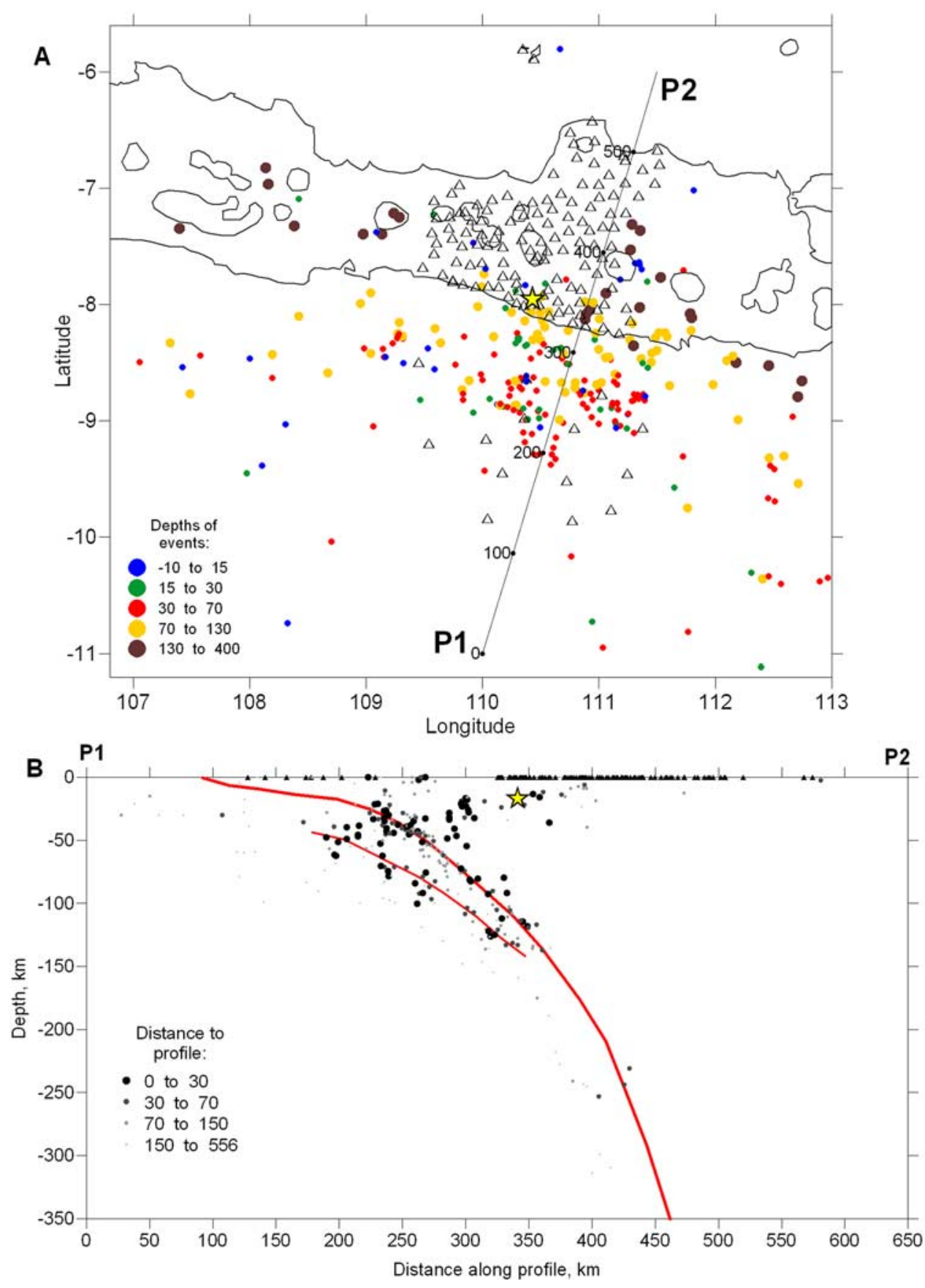

Figure 2. Distribution of events and stations used in this study. (a) Map view. Black open triangles indicate position of stations installed within the MERAMEX project. Colored dots show the distribution of events with depths according to the scale. The star shows the hypocenter of Bantul $\mathrm{M}_{\mathrm{w}}=6.5$ earthquake (26.05.2006 UTC). (b) Distribution of the events and stations in a cross section which positions are shown in Figure $2 \mathrm{a}$. Intensity of dots reflects distance of the events to the profile. Red lines mark surface of the slab and position of a double seismic zone.

anisotropic media with one predefined vertical orientation. This algorithm presumes anisotropy for only $P$ velocity described as horizontally oriented ellipsoid. We do not perform full inversion for an arbitrary orientation of the main anisotropy axes in 3-D. Such approximation requires too many free parameters (at least six parameters as in the work of Bokelmann [2002]) which cannot be well resolved using the existing ray coverage. In the local earthquake scheme, there is strong tradeoff effect between source parameters and velocity, and it makes problematic deriving vertical anisot- 


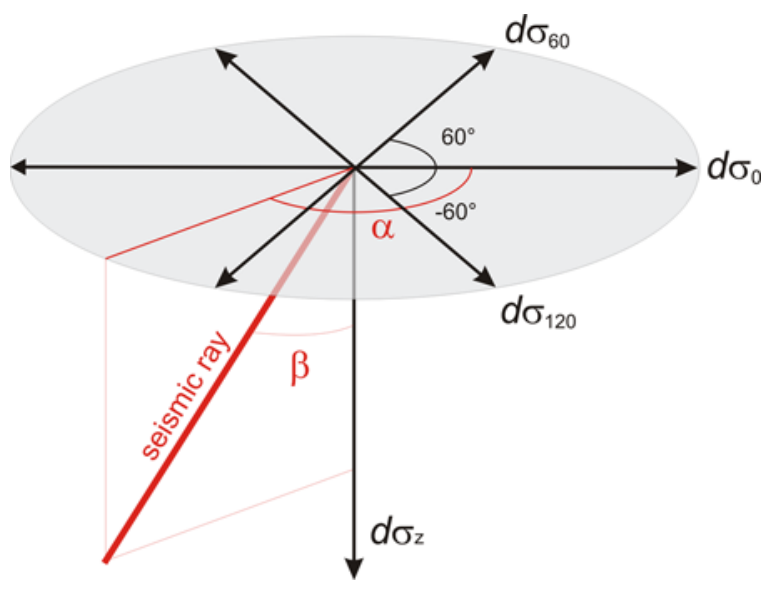

Figure 3. Sketch for the definition of the anisotropic model.

ropy parameters. On the contrary, horizontal anisotropy components are computed more robustly. For $S$ velocity we presume an isotropic model because studying $S$ anisotropy requires making observations of fast and slow shear waves, their orientations, and splitting times. The data quality does not allow performing this analysis using the standard picking tools.

[13] At each point, seismic $P$ velocity depends on the ray orientation and its special distribution is represented by an ellipsoid with three orthogonal main axes. One of them is oriented vertically while the other two are in the horizontal plane. As a result of tomographic inversion, four parameters are determined for each point of the study volume. Three of them, $d \sigma_{0}, d \sigma_{60}, d \sigma_{120}$, are variations of slowness with respect to the reference slowness value, $\sigma_{r e f}$, in the horizontal plane along three different azimuthal directions: $0^{\circ}, 60^{\circ}$ and $120^{\circ}$, respectively, as shown in Figure 3. The fourth parameter, $d \sigma_{v e r}$, is a slowness variation along the vertical axis. Using these four parameters, slowness along a ray, with the azimuth, $\alpha$, and dipping angle, $\beta$, (measured upward from the vertical axis) can be represented as:

$$
\sigma=\sigma_{\text {ref }}+\left(d \sigma_{\text {hor }} \sin \beta+d \sigma_{\text {ver }} \cos \beta\right) /(\sin \beta+\cos \beta)
$$

where

$$
\begin{aligned}
d \sigma_{\text {hor }} & =d \sigma_{1}+d \sigma_{2}+d \sigma_{3} \\
d \sigma_{1} & =\frac{1}{3}[\cos (2 \alpha)+1] d \sigma_{0} \\
d \sigma_{2} & =\frac{1}{3}\left[\cos \left(2\left(\alpha-\frac{\pi}{3}\right)\right)+1\right] d \sigma_{60} \\
d \sigma_{3} & =\frac{1}{3}\left[\cos \left(2\left(\alpha-\frac{\pi}{3}\right)\right)+1\right] d \sigma_{120}
\end{aligned}
$$

It can be easily checked that for the isotropic case, if $d \sigma_{0}=d \sigma_{60}=d \sigma_{120}=d \sigma_{v e r}$, slowness would be equal to $d \sigma_{0}$, regardless of the orientation of the rays.

[14] In general, the ANITA algorithm uses a similar strategy as the LOTOS-06 code, which is described in detail by Koulakov et al. [2007]. The structure of the algorithm is shown in

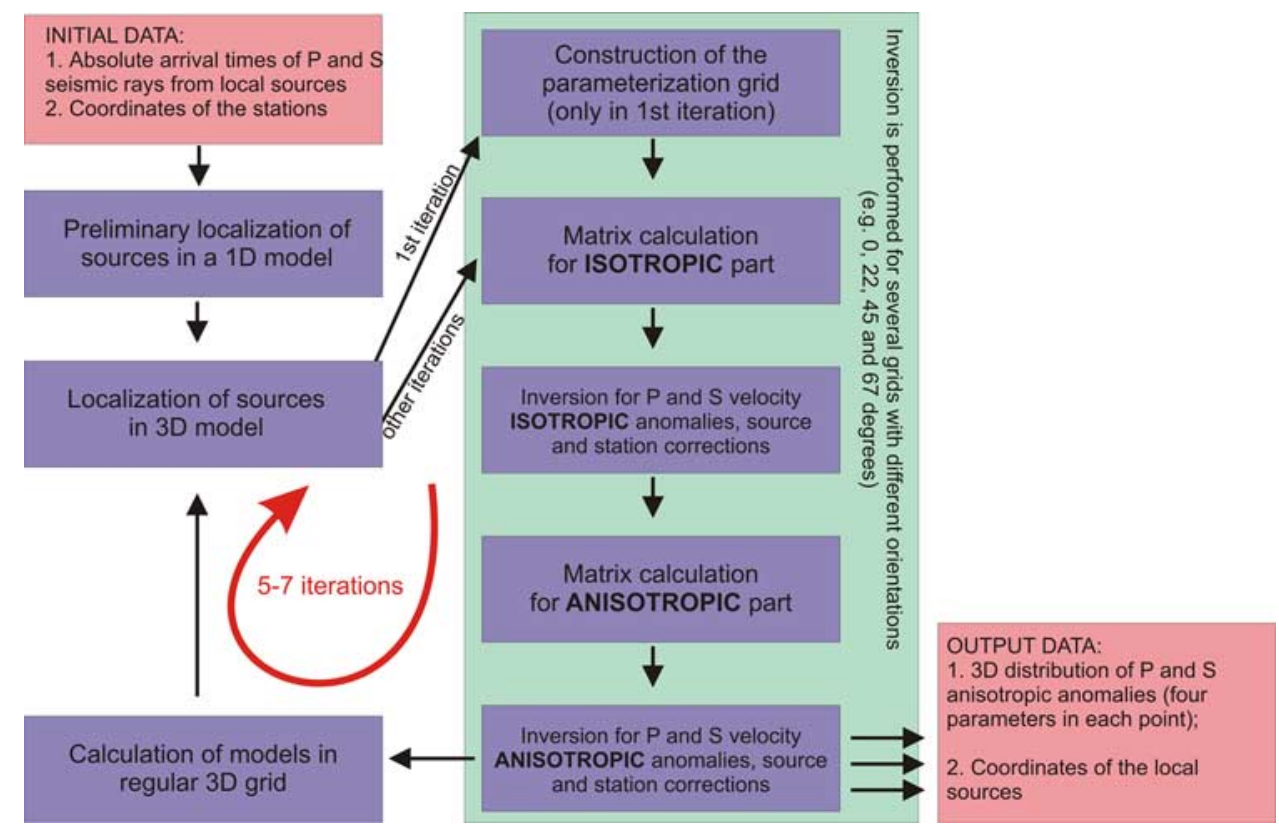

Figure 4. Block scheme of the ANITA algorithm. 
Table 1. One-Dimensional Velocity Distribution Used as Starting Reference Model in This Study

\begin{tabular}{ccc}
\hline Depth, $\mathrm{km}$ & $V p, \mathrm{~km} / \mathrm{s}$ & $V s, \mathrm{~km} / \mathrm{s}$ \\
\hline-3 & 4.30 & 2.47 \\
3 & 4.90 & 2.81 \\
8 & 5.70 & 3.27 \\
16 & 6.90 & 3.96 \\
24 & 7.10 & 4.08 \\
77 & 7.8 & 4.48 \\
120 & 8.05 & 4.62 \\
165 & 8.17 & 4.69 \\
210 & 8.30 & 4.77 \\
260 & 8.48 & 4.87 \\
310 & 8.66 & 4.97 \\
\hline
\end{tabular}

Figure 4. The processing starts with the preliminary location of the sources using tabulated traveltimes of a 1-D model. $P$ velocity in the 1-D reference model in the crust has been constructed according to a priori information [Wagner et al., 2007]. One-dimensional distribution of the reference $S$ velocity has been derived from optimization of the $\mathrm{Vp} / \mathrm{Vs}$ ratio which provided the best data fit (1.74). The velocity values in the starting 1-D model which was used in this study are presented in Table 1. Velocity is defined at some depth levels and linearly interpolated in between.

[15] At each iteration we perform relocation of sources based on 3-D ray tracing in the updated anisotropic model. There are several algorithms for ray tracing in an arbitrary anisotropic model [e.g., Iversen and Psencýk, 2008; Farra and Psencýk, 2008]. However, we use a simplified version of the ray tracing algorithm which is based on Fermat principle consisting in finding the path which provides minimal traveltime. After $U m$ and Thurber [1987] this approach is called bending method. We have implemented a version of this algorithm that allows for a very general description of the velocity model. For the isotropic case it is described in detail in the work of Koulakov [2009]. For the anisotropic model, the main principle of the tracing algorithm remains the same. When we compute the traveltime as integral along a path between source and receiver, in each point of the path the velocity is computed according to orientation:

$$
T=\int_{p a t h} \sigma(\alpha(s), \beta(s)) d s
$$

For azimuth $\alpha$ and incidence angle $\beta$ in a current point $s$, the slowness $\sigma$ is computed according to equations (1) and (2). After iterative 3-D deformations of the curves between a source and a receiver we obtain the raypath for which the integral in equation (3) is minimal. This bending algorithm allows using any representations of the velocity model in which one positive velocity value, in isotropic case, and four values, for anisotropic case, were defined uniquely at each point of the $3-\mathrm{D}$ study volume. The velocity distribution can be defined either at nodes with fixed interpolation laws, or in cells with constant or gradient velocity, or parameterized in polygons with predefined analytical distributions, or in any other way.

[16] In the ANITA algorithm, parameterization is performed using Cartesian coordinates by subdividing the study volume into rectangular cells of variable size according to the ray density (summary ray length is a unit volume). The block size becomes larger if the ray density is lower. Practical realization of grid construction is based on iterative subdivision of parallelepipeds in to two equal parts along $x, y$, and $z$ directions, one after another. The procedure starts with the entire study volume and ends when the block size becomes smaller than a predefined value of minimal spacing. In each iteration, the block subdivision is performed only if the summary length of rays inside a current block is larger than a predefined value (e.g., 2 times of average ray density). If the block size is larger than a predefined value (e.g., $50 \mathrm{~km}$ of diagonal), this block is not considered for the inversion. A similar approach has been used in some regional [e.g., van der Hilst and Engdahl, 1991] and global [e.g., Bijwaard et al., 1998] studies. In our previous study [Koulakov et al., 2007] we used another parameterization method, namely one based on nodes connected with each other by tetrahedral cells. The resulting images obtained with these two parameterization methods can be compared with each other, and this gives another idea about the robustness of the solution. The ANITA code allows inversion for several differently oriented grids (e.g., for $0^{\circ}, 22^{\circ}, 45^{\circ}$, and $67^{\circ}$ orientations). Figure 5 shows examples of two grids oriented along $0^{\circ}$ and $45^{\circ}$ at the depth of $15 \mathrm{~km}$. Averaging the results obtained for different grids decreases the artifacts related to block configuration. For $P$ and $S$ velocity distributions, the grids are constructed independently.

[17] Examples of grids with $8 \mathrm{~km}$ and $4 \mathrm{~km}$ of minimal lateral spacing are presented in the upper row of Figure 5 (map view) and in Figure 6 (cross section). In these cases number of cells which were 

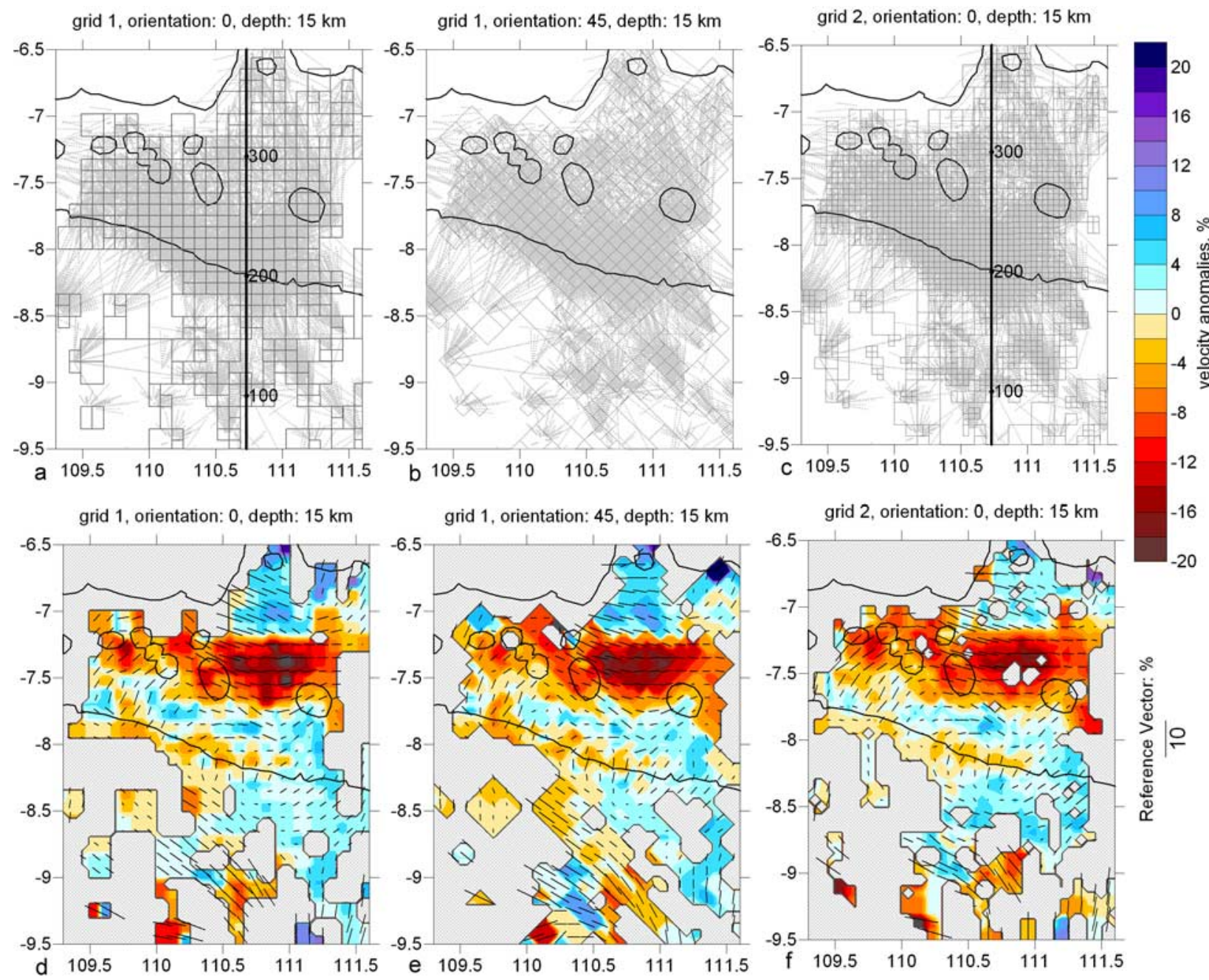

Figure 5. Examples of different parameterization grids and their effect on the inversion results. $(a, b, d$, and e) Coarse grid with $0^{\circ}$ and $45^{\circ}$ orientations; (c and f) fine grid with $0^{\circ}$ orientation. Figures $5 \mathrm{a}-5 \mathrm{c}$ show configurations of three grids at $15 \mathrm{~km}$ depth according to ray density. Grey dots mark the raypaths in the depth interval between 10 and $20 \mathrm{~km}$. Figures $5 \mathrm{~d}-5 \mathrm{f}$ present the inversion results for $P$ velocity anomalies at the depth of $15 \mathrm{~km}$. Colors indicate isotropic anomalies; bars show orientations of fast velocity in horizontal projection. Lengths of the bars reflect values of horizontal anisotropy.

used for inversion was $\sim 5800$ and $\sim 32,053$, respectively. Note that in the second case number of cells was larger than the amount of data. However, it does not cause any problem because the parameters in different cells are not independent and linked with each other through an additional smoothing matrix block (see description of the inversion algorithm below). In this case an $F$ test, which is usually used to estimate the quality of iterative inversion [Draper and Smith, 1966], seems to be inappropriate because of negative difference between amounts of data and parameters.

[18] Calculation of the first derivative matrix is performed numerically along the rays traced from current source locations in 3-D anisotropic model.
The elements of the matrix, which are equal to the traveltime variations of a ray due to the unit variations of each of the four slowness components in each parameterization block, are computed as

$$
d t_{i}=S_{i j} d \sigma_{j}(\alpha, \beta)
$$

where $S_{\mathrm{ij}}$ is the length of the $i$ th ray in the $j$ th cell, and $d \sigma_{\mathrm{j}}$ is the slowness variation along the ray (with azimuth $\alpha$ and dipping angle $\beta$ ) related to the unit variation of one of the four slowness components in the $j$ th cell, which is computed using equations (1)-(2).

[19] The inversion is performed simultaneously for $P$ and $S$ anomalies (four components for each 

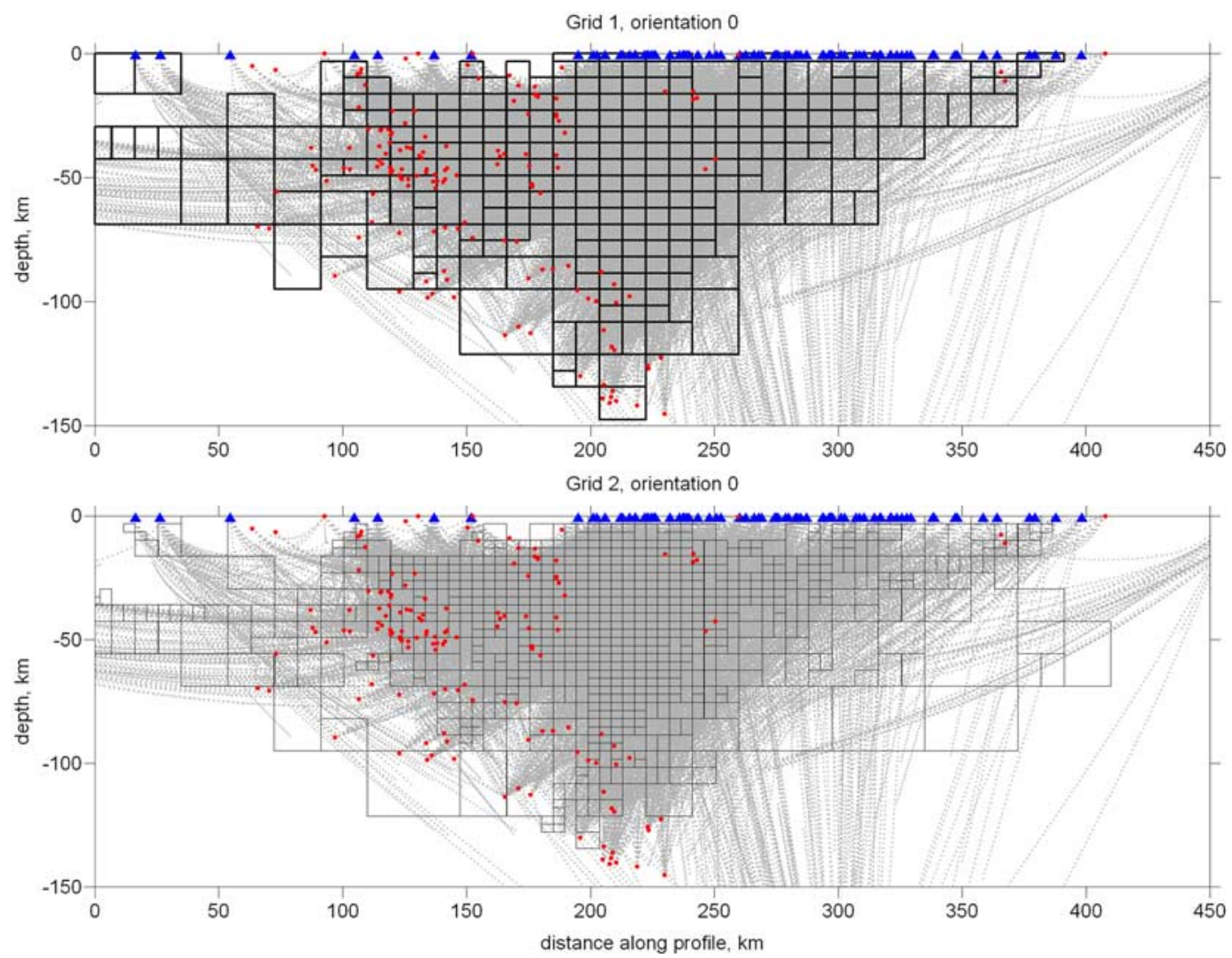

Figure 6. Coarse and fine parameterization grids corresponding to models 1 and 2 (Figures 5a, 5c, 5d, and 5f) in a cross section with the position indicated in Figures $5 \mathrm{a}-5 \mathrm{c}$. Grey dots mark the raypaths in the band of $100 \mathrm{~km}$ thick around the profile. Red dots indicate the sources; blue triangles depict stations.

block) and the source corrections (four parameters for coordinates and origin time). The main system of linear equations has the following structure.

$$
\begin{aligned}
& \frac{\partial t_{i}}{\partial \sigma_{j}^{P 0}} d \sigma_{j}^{P 0}+\frac{\partial t_{i}}{\partial \sigma_{j}^{P 00}} d \sigma_{j}^{P 60}+\frac{\partial t_{i}}{\partial \sigma_{j}^{P 120}} d \sigma_{j}^{P 120} \frac{\partial t_{i}}{\partial \sigma_{j}^{P z}} d \sigma_{j}^{P z} \\
& +0+W^{\text {Srce }} \frac{\partial t_{i}}{\partial h_{k}} d h_{k}=d t_{i}^{P} \\
& 0+\frac{\partial t_{i}}{\partial \sigma_{j}^{S}} d \sigma_{j}^{S}+W^{S r c e} \frac{\partial t_{i}}{\partial h_{k}} d h_{k}=d t_{i}^{S}
\end{aligned}
$$

Each line contains three groups corresponding to different unknown parameters marked by frames. Column 1 represents the anisotropic $P$ slowness anomalies which include four values in each parameterization block. Column 2 contains isotropic $S$ slowness anomalies, one value in each block. Column 3 represents the source parameter corrections, $d h_{k}$, which describe source coordinates and origin time. $d \sigma_{j}^{P k}$ is one of four components $(k=1 \ldots 4)$ of the $P$ slowness perturbations in the $j$ th block; $d \sigma_{j}^{S}$ is the $S$ slowness perturbations in the $j$ th block; $W^{\text {srce }}$ is the weight for the source parameters and $d t_{i}^{\mathrm{P}(S)}$ is the observed $P(S)$ residual along the $i$ th ray.
[20] The amplitude and smoothing of the model is controlled by several supplementary matrix blocks. The first two blocks control the amplitude of the anomalies and consist of diagonal matrices. The corresponding data vector is zero:

$$
\begin{aligned}
& A m p \_P d \sigma_{j}^{P}+0+0=0 \\
& 0+A m p \_S d \sigma_{j}^{S}+0=0
\end{aligned}
$$

$A m p \_P$ and $A m p \_S$ are the coefficients that control the amplitude levels of the $P$ and $S$ anomalies.

[21] The next matrix blocks aim at smoothing the slowness components in space. For two neighboring cells, $m$ and $n$, the following equations are defined for the $P$ and $S$ models:

$$
\begin{aligned}
& \text { Sm_hor_P }\left(d \sigma_{m}^{P 0}-d \sigma_{n}^{P 0}\right)+0+0=0 \\
& \text { Sm_hor_P }\left(d \sigma_{m}^{P 60}-d \sigma_{n}^{P 60}\right)+0+0=0 \\
& \text { Sm_hor_P }\left(d \sigma_{m}^{P 120}-d \sigma_{n}^{P 120}\right)+0+0=0 \\
& \text { Sm_ver_P }\left(d \sigma_{m}^{P z}-d \sigma_{n}^{P z}\right)+0+0=0 \\
& 0+S m \_S\left(d \sigma_{m}^{S}-d \sigma_{n}^{s}\right)+0=0
\end{aligned}
$$


where $S m$ hor $P$ and $S m$ ver $P$, are the coefficients that control the smoothing of the horizontal and vertical components of slowness for the $P$ models. $S m_{-} S$ controls smoothing of the $S$ model.

[22] In addition, it is possible to control the anisotropy level within each parameterization cell using the following equations:

$$
\begin{aligned}
& \text { Sm_an_P }\left(d \sigma_{m}^{P 0}-d \sigma_{m}^{P 60}\right)+0+0=0 \\
& S m \_a n \_P\left(d \sigma_{m}^{P 0}-d \sigma_{m}^{P 120}\right)+0+0=0 \\
& \text { Sm_an } P\left(d \sigma_{m}^{P 0}-d \sigma_{m}^{P z}\right)+0+0=0
\end{aligned}
$$

where $S m \_a n \_P$ and $S m \_a n \_P$, are the coefficients which control the anisotropy amplitude (difference between maximum and minimum velocity perturbations) within each cell. Increasing these coefficients forces the model to be more isotropic. The ANITA code allows inversion using any combination of the supplementary blocks in equations (6)-(9). The inversion of the entire matrix is performed using the LSQR method [Paige and Saunders, 1982; Van der Sluis and van der Vorst, 1987].

[23] The ANITA algorithm also provides the possibility of performing the inversion for an isotropic model. In this case it becomes similar to the LOTOS-06 algorithm, except for the parameterization method which differs for these two codes. Consequently, isotropic and anisotropic inversions can be combined within one iteration step as shown in Figure 4. In this case the isotropic inversion is performed first, then the time residuals are corrected, and the anisotropic inversion is performed. The resulting model is computed as a sum of isotropic and anisotropic parts. We have performed the inversion using different schemes: combined isotropic-anisotropic, only anisotropic, first isotropic (one to four iterations) and then anisotropic (five to seven iterations). All of them provided similar results that show the robustness of the method. However, performing the combined approach seems to be preferable because it allows evaluating the contribution of anisotropy in improving the data fit and determining the optimum relationships between the isotropic and anisotropic parts.

[24] After calculating the slowness components for the differently oriented parameterization grids, the obtained results are averaged into one regular 3-D grid. This model is used as the basic velocity model for the next iteration. The next iteration contains source location for new anisotropic $P$ and isotropic $S$ models, matrix calculation and inversion. In this case, the parameterization grids remain the same as in the first iteration. The results presented below are obtained after five iterations.

[25] We have thoroughly tested the algorithm to evaluate the effect of different parameters upon the results. Some of these tests are presented in the next section.

[26] The resulting maps for a $P$ model, which will be shown in the next section, present both isotropic and anisotropic parts of the derived velocity fields. The isotropic velocity variations are computed as:

$$
d v_{i s o}=\frac{1}{4}\left[d v_{z}+3 \overline{d v}_{h o r}\right]
$$

where $\overline{d v}_{h o r}$ is the average velocity anomaly in the horizontal plane which is derived as:

$$
\overline{d v}_{h o r}=\frac{1}{\pi} \int_{-\pi / 2}^{\pi / 2} d v_{h o r}(\alpha) d \alpha
$$

$d v_{\text {hor }}(\alpha)$ is computed according to equations (1)(2) with the dipping angle $\beta=\pi / 2$.

[27] The anisotropy in the resulting horizontal sections is illustrated by bars. Orientations of bars show the direction of the main anisotropy axis in which the horizontal velocity is maximal. The length of the bars reflects the magnitude of the anisotropy, which is computed as:

$$
A^{\text {hor }}(\%)=100\left(d v_{\max }-d v_{\min }\right) / V_{\text {ref }}
$$

where $d v_{\max }$ and $d v_{\min }$ are the maximum and minimum velocities in the horizontal plane and $V_{\text {ref }}$ is the reference velocity.

[28] In vertical sections, the bars reflect the values of vertical anisotropy which is computed as:

$$
A^{v e r}(\%)=100\left(d v_{z}-\overline{d v}_{h o r}\right) / V_{\text {ref }}
$$

It should be pointed out that in our anisotropic model one axis of the anisotropic ellipsoid is always oriented vertically. Thus the bars in the cross section are either vertical if $\mathrm{A}^{v e r}(\%)>1 \%$, or horizontal if $\mathrm{A}^{\text {ver }}(\%)<-1 \%$. In the cases of absolute value of anisotropy less than $1 \%$, the bars are not shown.

\section{Results}

[29] In Figures 7-8 we present the anisotropic $P$ and isotropic $S$ models which are obtained after 
Geochemistry

Geophysics

KOULAKOV ET AL.: ANISOTROPIC STRUCTURE OF CENTRAL JAVA $10.1029 / 2008$ GC002109

Geosystems U
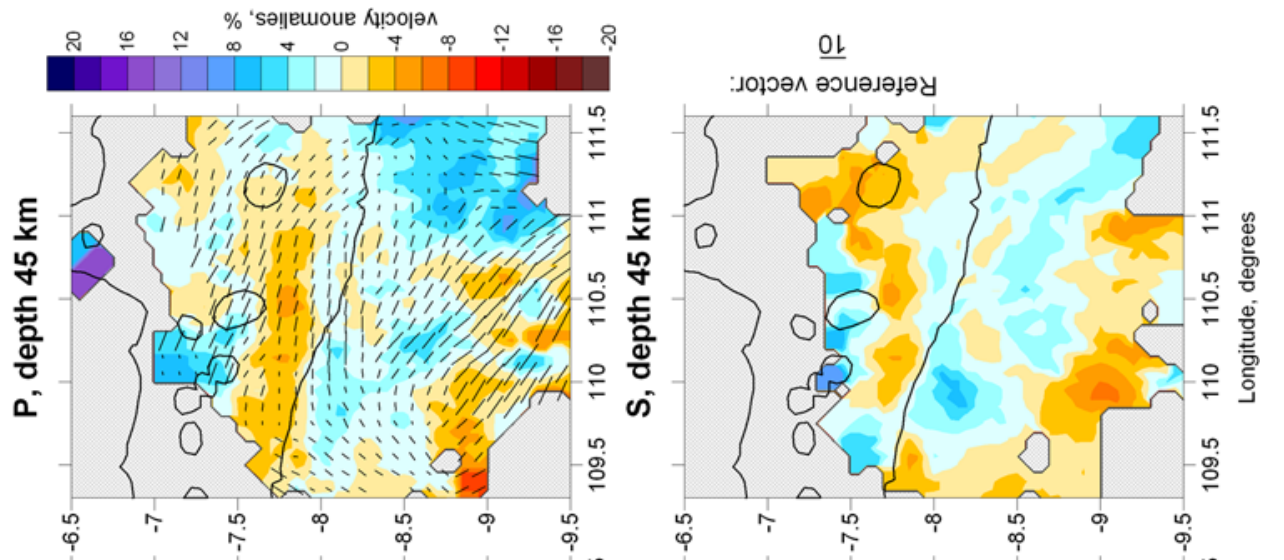

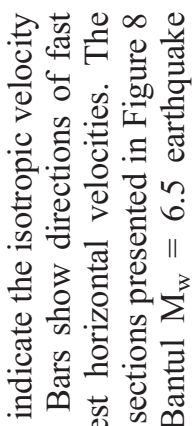
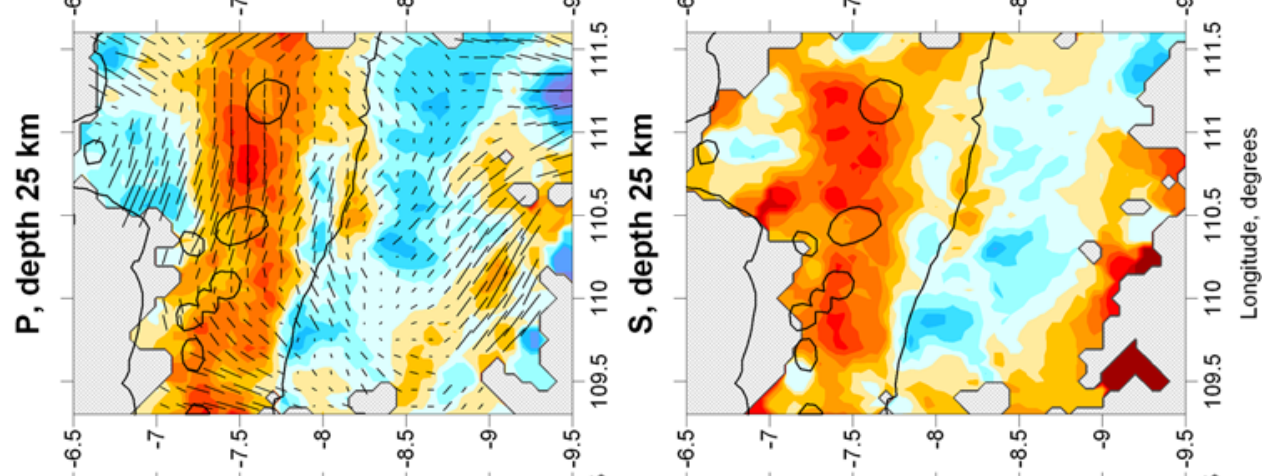

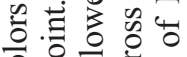

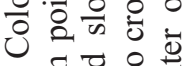

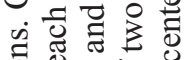

.

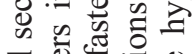

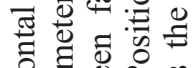

के है요

站苛完

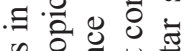

记
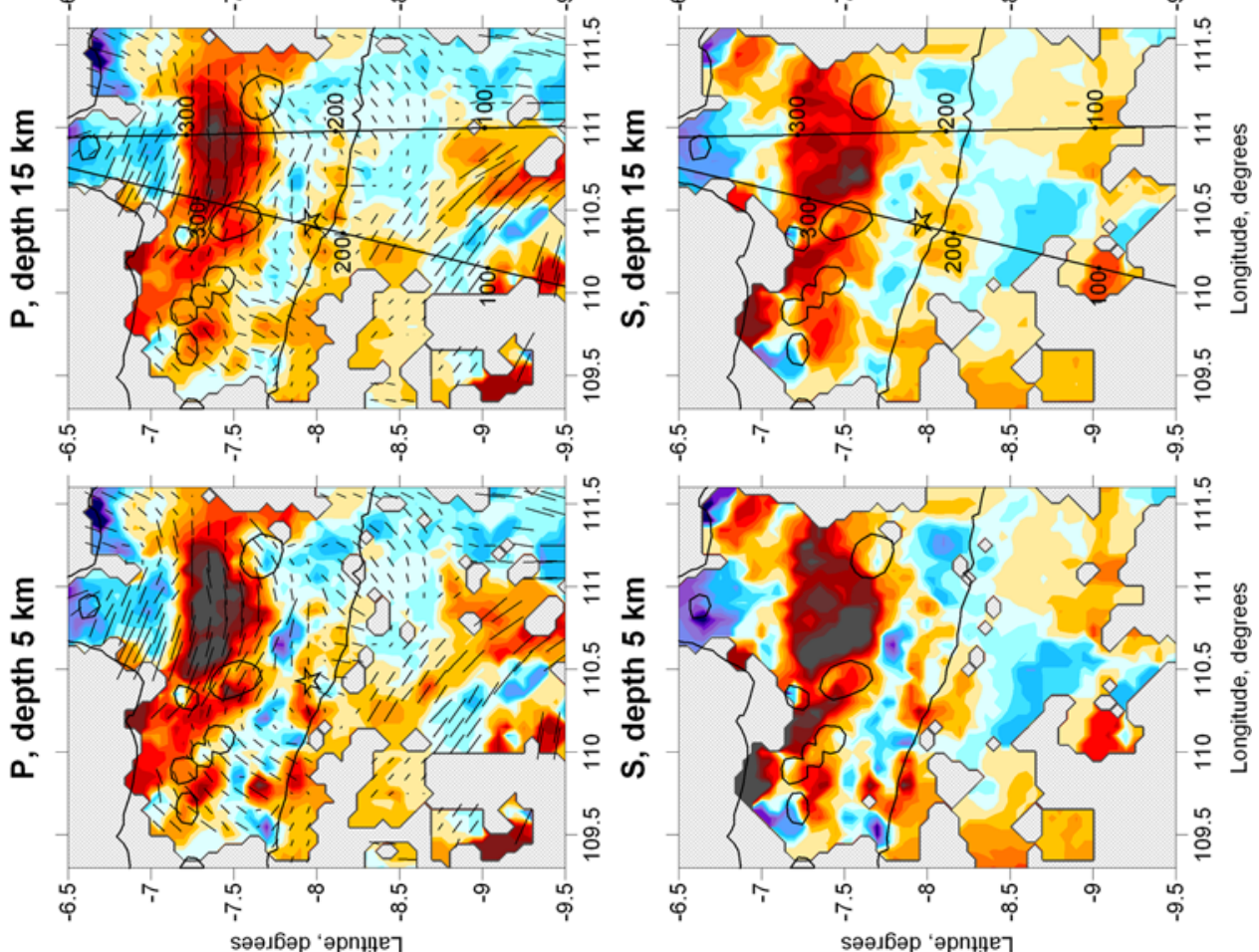

跑志志志

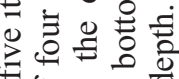

它

过

흏ํㄴ

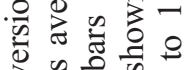

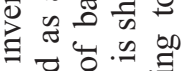

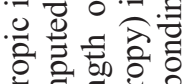

言造造 䒕柁志 पै

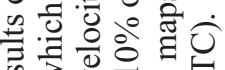

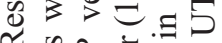

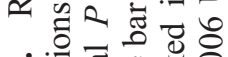
$\therefore$ 율 可

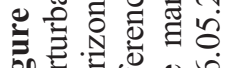

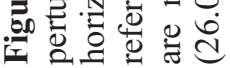



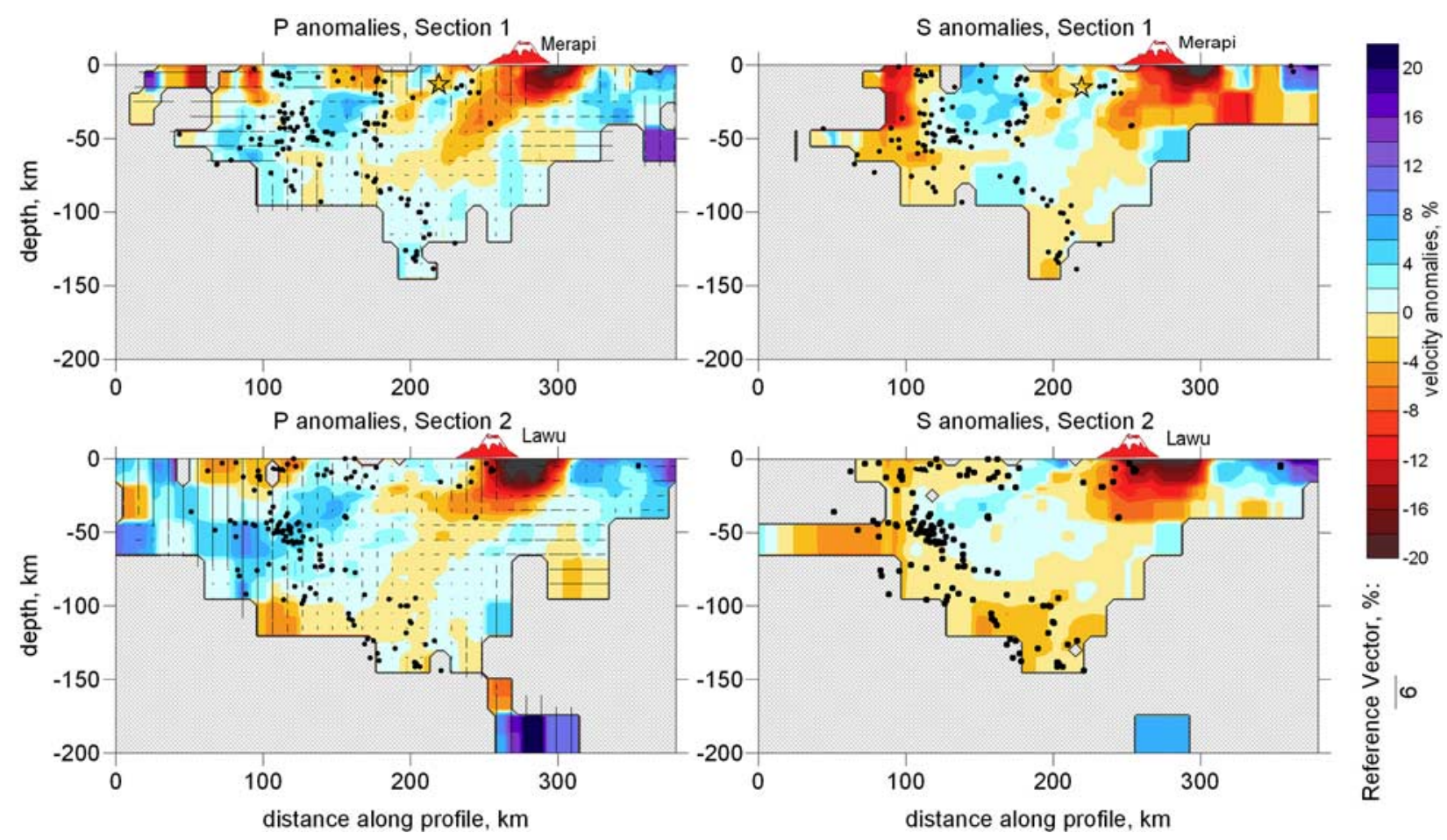

Figure 8. Resulting anisotropic $P$ and isotropic $S$ models after five iterations in vertical sections. Positions of sections are shown in map related to $15 \mathrm{~km}$ depth (Figure 7). The anisotropy bars for the $P$ model are vertical if the vertical velocity variations are larger than the average horizontal perturbations and horizontal in the opposite case. The reference bar ( $6 \%$ of anisotropy) is shown in the bottom left corner.

inversion of the observed data and which can be considered as the main result of this study. These models are derived after five iterations. They are the average of four models computed for differently oriented parameterization grids. In the case of the $P$ model, the bars in horizontal sections show the alignment of the fastest horizontal velocity. In some parts of the crust the anisotropy value reaches $10 \%$. In the vertical sections the anisotropic bars are oriented either vertically or horizontally, depending on the largest component of anisotropy.

[30] The results for $5 \mathrm{~km}$ depth are possibly representing the integral effect of velocity anomalies in the depth interval of $0-\sim 10 \mathrm{~km}$. As shown in the work of Koulakov et al. [2007], the differences between isotropic anomalies at 5 and $10 \mathrm{~km}$ depth are hardly resolved. For the anisotropic patterns the resolution is worse; thus similar anisotropic patterns observed at 5 and $15 \mathrm{~km}$ depth may be due to poor vertical resolution in the uppermost part.

[31] The most important feature of this model is a prominent low-velocity anomaly which is observed in the central part of Java, just north of the Merapi and Lawu volcanoes. This anomaly has already been described in the previous study by Koulakov et al. [2007] and was called the Merapi-Lawu
Anomaly (MLA). At $10 \mathrm{~km}$ depth the velocity difference between the MLA and the forearc reaches $30 \%$ for the $P$ and $35 \%$ for the $S$ model. In the previous study we have thoroughly tested the results in order to show the reliability of these amplitudes. In the present study, the shape and amplitude of this anomaly are similar to the previous results. At depths down to $15 \mathrm{~km}$, MLA extends along a wide area between $109.5^{\circ}$ and $110.3^{\circ}$ longitude. The interior structure of this anomaly is apparently not homogeneous. At 5 and $15 \mathrm{~km}$ depth we observe few local highervelocity anomalies that line up in the NW direction and coincide with the Sumbing-Sundoro-Dieng and Merapi-Merbabu-Telomoyo volcanic chains. Such small anomalies are just within the lower limit of the resolution power of the method. However, as we can see from the test with odd-even number of events presented below, these features are stably resolved for two independent data sets, and therefore they are reliable.

[32] In the vertical sections (Figure 8) we can see that the MLA prolongs into the mantle and shifts southward with depth. In the previous study we did not detect this feature deeper than $50 \mathrm{~km}$. Now, owing to higher quantity and quality of data we can 
resolve it much deeper. According to these results, the MLA seems to be linked with the earthquakes cluster at $110-130 \mathrm{~km}$ depth through an inclined low-velocity anomaly which is observed in both the $P$ and $S$ models. Reliability of this feature is checked using synthetic modeling in the next section.

[33] In the both vertical sections, the events in the slab seem to be aligned along a double seismic zone. In section 1 , the events above $50 \mathrm{~km}$ depth are located around a high-velocity block, located between $110 \mathrm{~km}$ and $170 \mathrm{~km}$ along the profile. Beneath the Lawu Mount (section 2), we also observe an important cluster of earthquakes, which seems intriguing since this volcano is considered dormant.

[34] The bars of maximum horizontal $P$ velocities are shown in Figure 7. We observe clear E-W oriented anisotropy with $7-10 \%$ of amplitude at all depth levels. In the forearc (onshore and offshore) the $P$ velocity anisotropy is much weaker. The southernmost segment appears to be strongly anisotropic with fast velocities trending NW and $\mathrm{N}-\mathrm{S}$. However, as will be shown in the testing section, the resolution in this part, especially for anisotropic parameters, is low. At $45 \mathrm{~km}$ depth and deeper, the $P$ velocities are faster in W-E direction for the whole area.

[35] The vertical section in Figure 8 also reveals some important anisotropic features. The most interesting structure is just beneath the Merapi and Lawu volcanoes, where we observe vertically oriented anisotropy of $P$ velocity for both sections. In contrast, in the MLA, the anisotropy is oriented horizontally. In the southern part of the study area, both profiles show fairly strong anisotropy with opposing orientations. However, all the tests, which will be shown later, reveal fairly low reliability for anisotropy reconstruction in this area.

[36] It seems important to compare the results of isotropic and anisotropic inversions in order to evaluate the contribution of the anisotropic part in improving the data fit. In Figure 9 we present the resulting $P$ velocity anomalies obtained from the isotropic inversion performed with the ANITA code (only one velocity parameter for each block). In both isotropic and anisotropic cases the data set is the same. The isotropic velocity anomalies in Figure 7 corresponding to the $P$ anisotropic model and the isotropic model in Figure 9 are very similar. It means that ignoring anisotropy does not cause any bias to the isotropic component, at least in the current case. This model is quite similar to the results in the work of Koulakov et al. [2007] obtained using the LOTOS-06 code. The main difference between these codes is the parameterization (cells and nodes). Thus, these results show that the inversion is robust regardless of parameterization.

[37] In Table 2 we present the $P$ and $S$ residuals after the iterative inversion for the cases of anisotropic $P$ and isotropic $S$ models (Figures 7 and 8) and isotropic $P$ and $S$ models (Figure 9). $S$ residuals in both cases are similar, therefore, for the first case, we show only $P$ residuals. The velocity structures (isotropic part) in isotropic and anisotropic models are generally consistent. For the first iteration the RMS of the residuals is computed just after the location (1-D isotropic model) and it is the same for both models. After five iterations the anisotropic model provides significantly smaller RMS $(0.177 \mathrm{~s})$ than in the isotropic model $(0.227 \mathrm{~s})$. This difference shows that in the central Java region, the contribution of anisotropy is fairly important. Note that for the isotropic model smaller RMS was obtained in this study compared to the previous results [Koulakov et al., 2007] that can be explained by stricter data selection.

[38] We have explored separate contributions of the mantle and crustal anisotropy upon the improvement of the data fit. We considered four different cases for the isotropic and anisotropic inversions listed in Table 3. "ISOTROP" is a fully isotropic model which is presented in Figure 9. "MODEL MAIN" is a fully anisotropic $P$ model, same as presented in Figure 7. In "MODEL_TEST1" and "MODEL_TEST2" the anisotropic inversion is performed only below and above $20 \mathrm{~km}$ depth, respectively. The values of the RMS of $P$ residuals for fully anisotropic, fully isotropic and two partly anisotropic cases are presented in Table 3 . According to these tests, $0.011 \mathrm{~s}(22 \%)$ of RMS improvement with respect to the isotropic model is due to the mantle anisotropy (MODEL_TEST1), and $0.038 \mathrm{~s}(76 \%)$ is due to the crustal anisotropy (MODEL_TEST2).

[39] However, small value of mantle anisotropy contribution does not mean that it is insignificant. Actually, large contribution of the crustal anisotropy is due to significantly larger amount of rays which travel through the crust. If we consider a ray from a deep source, the contribution of the mantle anisotropy might be much more important than that of the crust. Indeed, the retrieved anisotropy in the mantle and in the crust has the same order of magnitude $(5-10 \%)$. Thus the contribution of different parts of the study volume would be 


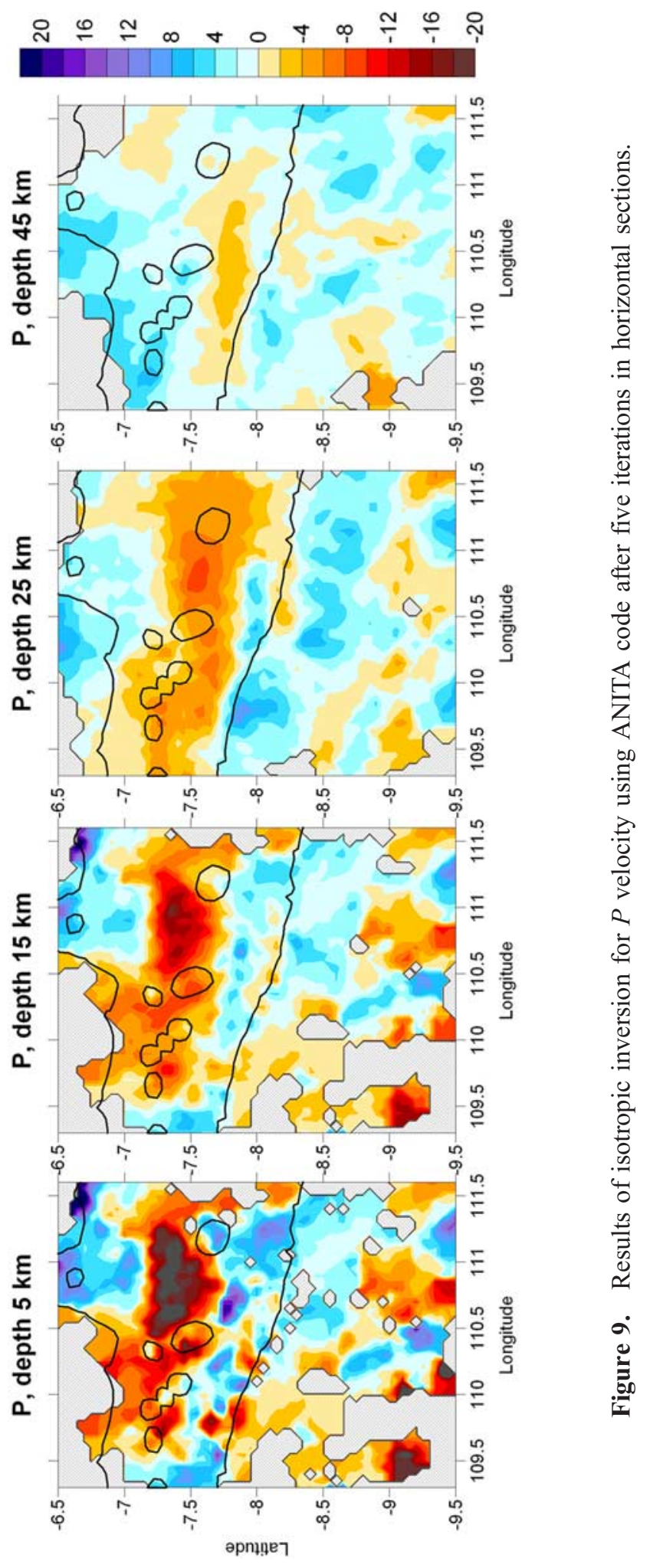


Table 2. RMS Values of $P$ and $S$ Residuals and Variance Reductions During Five Iteration Steps for Anisotropic and Isotropic Inversions Based on the ANITA Code

\begin{tabular}{|c|c|c|c|c|c|c|}
\hline \multirow[b]{2}{*}{ Iteration } & \multicolumn{3}{|c|}{$\begin{array}{c}\text { Anisotropic } P \text { and Isotropic } \\
S \text { Models (Figure 5) }\end{array}$} & \multicolumn{3}{|c|}{ Isotropic $P$ and $S$ Models } \\
\hline & $\begin{array}{l}\text { RMS } \\
\text { of } d t p\end{array}$ & $\begin{array}{c}\text { Variance } \\
\text { Reduction, } P, \%\end{array}$ & $\begin{array}{l}\text { RMS } \\
\text { of } d t p\end{array}$ & $\begin{array}{l}\text { RMS } \\
\text { of } d t s\end{array}$ & $\begin{array}{c}\text { Variance } \\
\text { Reduction, } P, \%\end{array}$ & $\begin{array}{c}\text { Variance } \\
\text { Reduction, } S, \%\end{array}$ \\
\hline 1 & 0.388 & 0 & 0.388 & 0.623 & 0 & 0 \\
\hline 2 & 0.242 & 37.67 & 0.287 & 0.429 & 26.14 & 31.12 \\
\hline 3 & 0.202 & 47.88 & 0.253 & 0.384 & 34.67 & 38.34 \\
\hline 4 & 0.186 & 51.89 & 0.238 & 0.364 & 38.73 & 41.43 \\
\hline 5 & 0.177 & 54.27 & 0.227 & 0.350 & 41.50 & 43.68 \\
\hline
\end{tabular}

roughly proportional to the length of the ray in each part. So if the segment of the ray in the mantle is five times longer than that in the crust, the contribution of the mantle anisotropy would be approximately five times stronger.

[40] One can argue that smaller RMS in the anisotropic inversion can be due to larger number of parameters and more freedom for fitting the residuals. Indeed, in the case of the anisotropic inversion we have four times more parameters than for the isotropic inversion. At the same time, we imply significantly more limitations for these parameters which are described by links between different parameters in equations (5)-(8). As a result, the inversion for the anisotropic model does not have much more freedom than in the isotropic case. The final isotropic perturbations which are derived from four anisotropic components have the same smoothness than in the isotropic case, and the anisotropic distribution (at least in map view) seems to be rather smooth and stable.

[41] The robustness of the derived pattern is tested by using parameterization grids with different characteristics. We tested different grid sizes and orientations, and in all cases the imaged anomalies remained quite stable. As an example, in lower row of Figure 5 we present the results based on two differently oriented grids $\left(0^{\circ}\right.$ and $\left.45^{\circ}\right)$ and another grid with two times smaller spacing. For the differently oriented grids (left and central columns), the $P$ anomalies configuration in the well resolved central area remains unchanged. Some minor differences at the margins of the study area disappear when we average the results computed for several differently oriented grids. For the grid with smaller spacing (right column), the number of cells for the $P$ model was about 32000 , that is larger than amount of $P$ picks. At the same time, it does not cause any trouble for the inversion. The retrieved anomalies are quite similar to those based on larger grids. The difference of RMS of the residuals after inversion in the coarse and fine grids was not significant $(0.177 \mathrm{~s}$ and $0.174 \mathrm{~s}$, respectively).

[42] The resulting amplitude of the anisotropy appears to be rather large (up to 10\%) both in the mantle and in the crust. However, we recommend considering these values with prudence. Indeed when we increased the damping of anisotropy (10 instead of 5 used in the main model), the maximal anisotropy reduced from $10-8 \%$ to $8-$ $6 \%$, without significant loss of data fit (the RMS increased from $0.177 \mathrm{~s}$ to $0.182 \mathrm{~s}$.) Such a tradeoff appears quite dangerous for considering the amplitude of the anisotropy at a quantitative level. Thus, the interpretation should be based on qualitative analysis (e.g., "stronger" or "weaker" anisotropy) and not on specific values of anisotropy. At the same time, orientation of the anisotropy appears to be robust regardless smoothing and other changes in the inversion conditions.

\section{Verification}

\subsection{Test With Odd and Even Numbers of Events}

[43] The contribution of random noise to the resulting images can be estimated by performing inde-

Table 3. Values of RMS of $P$ Residuals After Inversions in Different Isotropic and Anisotropic Models

\begin{tabular}{lc}
\hline \multicolumn{1}{c}{ Model Description } & $\begin{array}{c}\text { RMS } \\
\text { of dtp, s }\end{array}$ \\
\hline "ISOTROP": Isotropic model in the entire area & 0.227 \\
"MODEL_TEST1": Isotropic above 20 depth, & 0.216 \\
$\quad$ and anisotropic below & 0.189 \\
"MODEL_TEST2": Isotropic below 20 depth, & \\
$\quad$ and anisotropic above & 0.177 \\
$\begin{array}{l}\text { MODEL_MAIN": Anisotropic model in the } \\
\text { entire area }\end{array}$ & \\
\hline
\end{tabular}


pendent inversions of randomly separated data subsets [e.g., Koulakov and Sobolev, 2006]. In this test, the whole data set is divided into two subsets: with odd and even numbers of events. The structure of the processing algorithm and all free parameters for source location and inversion remain the same as in the case of inversion of the entire data set.

[44] Results of inversion for $P$ and $S$ models for odd and even events are shown in Figure 10, presented in horizontal sections. The models can be compared with each other and also with the results using the entire data set (Figures 7) to show the effect of data halving on the inversion results. The results of inversion for isotropic components of $P$ and $S$ models in the both 5 and $25 \mathrm{~km}$ depth sections show almost perfect correlation of the velocity structure. Even small patterns, less than $15 \mathrm{~km}$ of lateral size, are reliably reconstructed in both models. This gives us high confidence for the obtained $P$ and $S$ isotropic velocity anomalies.

[45] The anisotropic parameters seem to be less robust. In some parts of the study area, the difference in orientation of bars derived from inversion of odd and even data sets appears to be rather strong. Within the MLA, $P$ velocity anisotropy is generally oriented along the WE direction in both models and appears to be fairly robust for both the $5 \mathrm{~km}$ and $25 \mathrm{~km}$ depth sections. In the onshore forearc the anisotropy seems to be fairly weak for both cases. In the southernmost part strong NW oriented anisotropy is observed for both models; however, as will be shown by synthetic modeling, the resolution of these values is low. In the northern high-velocity block, large difference is observed between odd and even models, which indicates that the anisotropy reconstruction is not stable there.

[46] This test shows that the anisotropic parameters are much more affected by random noise and change of the ray configuration than the isotropic velocity variations. In our experiment we have a relatively small amount of events. Their subdivision into two subsets produces significantly different data configuration. We believe that to obtain more stable results for anisotropy, the data amount should be larger in order to produce statistically similar data subsets. In this stage, the results for anisotropy are robust only in the southern part of the onshore area where we have dense distribution of the stations and higher quality of the signal. In other areas the anisotropic results should be considered with prudence.
[47] The test with odd and even events is a supplementary verification method which can reveal problems that are not detected in the commonly used resolution tests. We encourage all tomography users to perform this fairly simple test in their studies.

\subsection{Synthetic Testing}

[48] As in the previous study [Koulakov et al., 2007], we pay special attention to synthetic testing. The ANITA algorithm allows definition of various synthetic models, either as periodical anomalies in a checkerboard test or manually by drawing polygons in the horizontal or vertical sections. For the $P$ anisotropic model, we define four parameters inside each anomaly which describe the anisotropic properties. It is convenient to define them in the following manner: $d V_{\max }$ is the maximum horizontal velocity variation; $d V_{\min }$ is the minimum horizontal velocity variation; $d V_{v e r}$ is the velocity variation in vertical direction; $\psi$ is the azimuth of the maximum velocity orientation.

[49] These four parameters can easily be converted to $d \sigma_{0}, d \sigma_{60}, d \sigma_{120}, d \sigma_{v e r}$ and then used to define anisotropic velocity according to equations (1)(2). The traveltimes for the synthetic tests are computed by the anisotropic version of 3-D ray tracing (bending) between sources and receivers corresponding to the real observation system. We add random noise with such magnitude that it provides the same variance reduction as after the real data inversion. After computing the synthetic traveltimes we "forget" the source positions and start the processing from the step in which the absolute location of events is performed. It is obvious that in this step the sources are shifted from their "true" position and the residuals are spoiled. After several iterations the algorithm should move them to their initial position and reproduce the velocity model. For the synthetic reconstructions, the values of the free parameters for performing source location, grid construction, and inversion are the same as those used for the real data inversion.

[50] To evaluate the sensitivity of the model related to the resolution of features in different parts of the study area, we performed checkerboard tests with different anomaly configurations. In Figure 11 we present the results for a model, "BRD $50 \mathrm{~km}$ ", in which the initial synthetic model is defined for the whole area as periodical anomalies of $50 \mathrm{~km}$ lateral size. These anomalies remain unchanged at all 


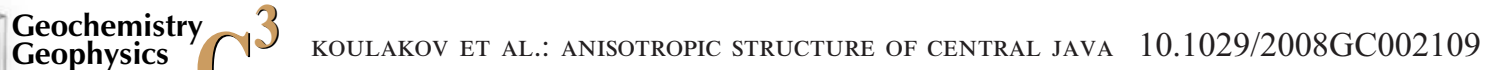

Geosystems $\circlearrowleft$

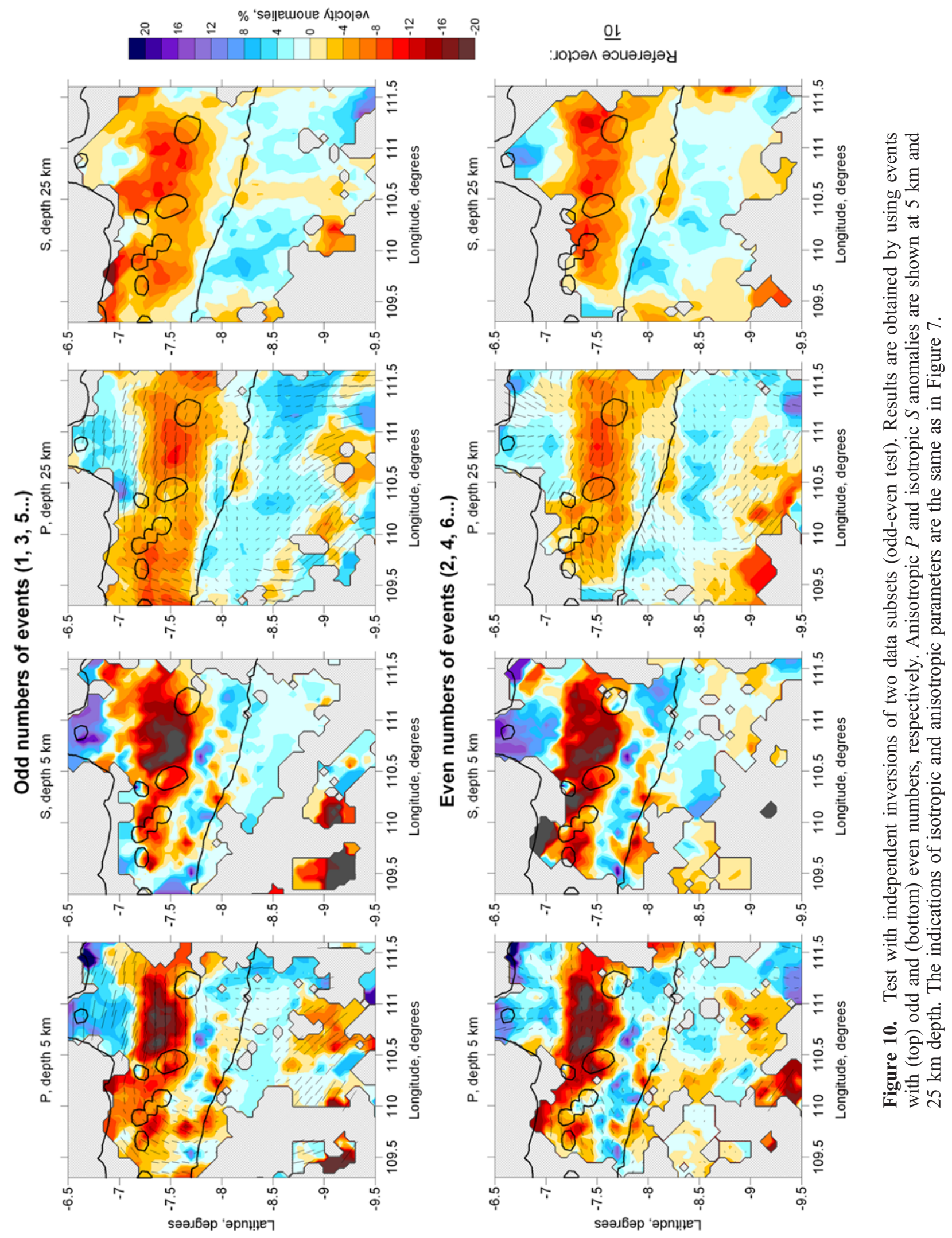




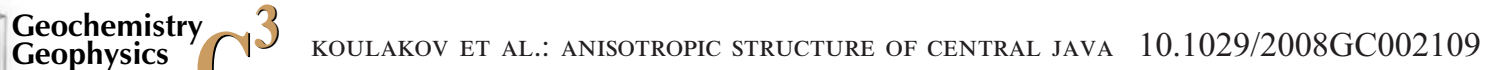
Geosystems
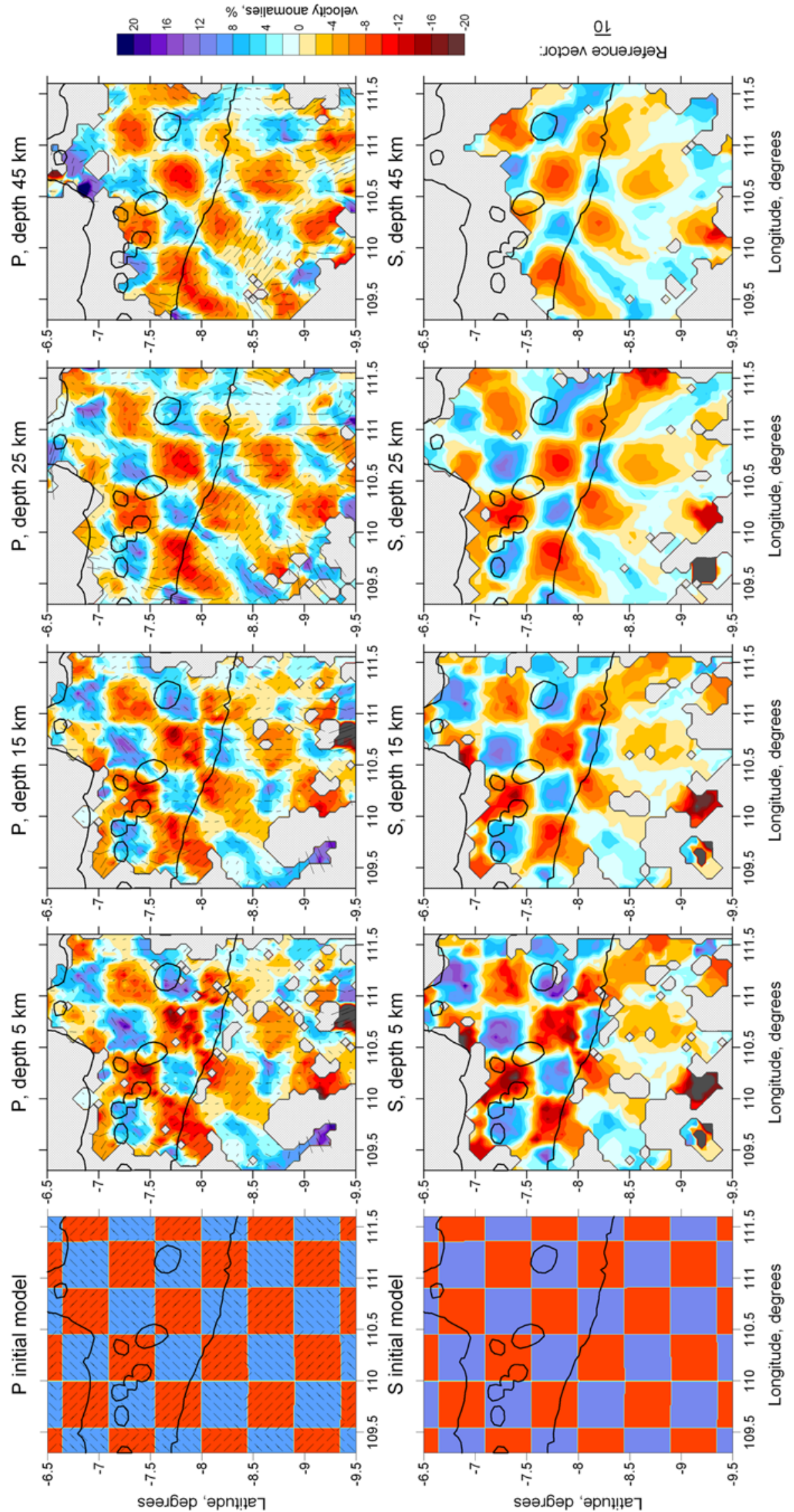

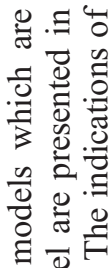

的范 잉 药 要远

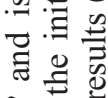
人. 을 즐 웜 青苛 त 증 寻五 ष舟 웡 웡 $\dot{m}$ ฮี ซี

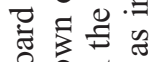

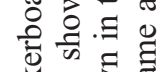

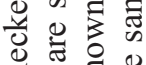
可 芒䒕 os 융ㄷㅇ 可 듈

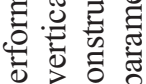

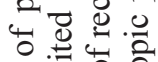

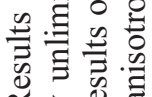
능 증 - $\overrightarrow{0}$ 它 氙

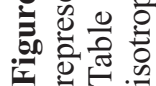


Table 4. Parameters of Five Synthetic Models Presented in This Study

\begin{tabular}{|c|c|c|c|c|c|c|c|c|}
\hline \multirow[b]{2}{*}{ Model } & \multicolumn{4}{|c|}{ "Blue" Anomaly } & \multicolumn{4}{|c|}{ "Red" Anomaly } \\
\hline & $d V_{\max }$ & $d V_{\min }$ & $d V_{v e r}$ & $\psi$ & $d V_{\max }$ & $d V_{\min }$ & $d V_{v e r}$ & $\psi$ \\
\hline BRD_50km & $15 \%$ & $5 \%$ & $7 \%$ & $45^{\circ}$ & $-5 \%$ & $-15 \%$ & $-7 \%$ & $-45^{\circ}$ \\
\hline BRD_30km & $15 \%$ & $5 \%$ & $7 \%$ & $45^{\circ}$ & $-5 \%$ & $-15 \%$ & $-7 \%$ & $-45^{\circ}$ \\
\hline SYN_HOR1 & $15 \%$ & $5 \%$ & $5 \%$ & $90^{\circ}$ & $-5 \%$ & $-15 \%$ & $-5 \%$ & $0^{\circ}$ \\
\hline SYN_HOR2 & $10 \%$ & $-5 \%$ & $-5 \%$ & $90^{\circ}$ & $10 \%$ & $-5 \%$ & $-5 \%$ & $0^{\circ}$ \\
\hline SYN_HOR3 & $10 \%$ & $10 \%$ & $10 \%$ & $0^{\circ}$ & $-15 \%$ & $-15 \%$ & $-15 \%$ & $0^{\circ}$ \\
\hline
\end{tabular}

\footnotetext{
${ }^{\text {a }}$ Models are shown in Figures 11 and 12. Here $d V_{\max }$ and $d V_{\min }$ are maximum and minimum horizontal velocity variations; $\psi$ is the azimuth of
} fast velocity orientation; $d V_{v e r}$ is vertical velocity variation.

depths. The anisotropic parameters inside the anomalies are shown in Table 4. Only two sorts of anomalies, "blue" and "red", are defined for this specific case. For the $S$ model we defined isotropic anomalies of $\pm 10 \%$ amplitude corresponding to the same patterns. In this test, we added random noise with 0.15 and $0.25 \mathrm{~s}$ RMS for $P$ and $S$ data, respectively.

[51] The results of the reconstruction of the anisotropic $P$ and isotropic $S$ velocity models after five iteration steps for four differently orientated grids are shown in Figure 11. In the crust, the best resolution is achieved beneath Java, where most of the onshore seismic stations were installed. For the offshore area, the ray geometry does not provide sufficient resolution to retrieve the model. In the deeper sections the size of the resolved area increases but the average quality of reconstruction decreases. It is important to note that in well resolved areas in the sections down to $25 \mathrm{~km}$ depth the anisotropic bars are reconstructed correctly. In the "red" and "blue" blocks they tend to be oriented in NW and NE directions respectively. In the deeper sections (e.g., $45 \mathrm{~km}$ depth) the reconstruction quality of the anisotropic parameters is much lower. In general, we can see that stability of the anisotropic parameter reconstruction is much lower than that of the isotropic model.

[52] In Figure 12 we present reconstruction results for four other anisotropic synthetic models. All the testing conditions were the same as for model "BRD_50 km", except for noise, which in the cases of model "SYN_HOR2" and "SYN_HOR3" was zero. In the first column we present another checkerboard test, "BRD_30 km", with $30 \mathrm{~km}$ block size and $20 \mathrm{~km}$ empty space between blocks. Although the periodicity of anomalies was, in this case, the same as in model "BRD_50 km", the reconstruction results for these two cases are clearly different. In the onshore area both isotropic and anisotropic components are reconstructed correctly.
[53] In the second column of Figure 12 we present model "SYN_HOR1", with free shape anomalies which roughly model the real situation. We define two types of anomalies and assign them significantly different isotropic and anisotropic parameters, listed in Table 4. The reconstruction results show that the isotropic part is reconstructed quite robustly. Both amplitudes and shapes of the isotropic anomalies are reconstructed correctly. The anisotropic bars seem to be less stable. However, we can clearly distinguish the anisotropic properties of the following structures: the isotropic offshore part, the southern "blue" anomaly, and the "red" anomaly in the center. The anisotropy in the northern "blue" block is not reconstructed correctly. The anisotropy retrieved in the offshore part, which was initially isotropic, is mostly due to random noise in the data.

[54] With the next two models we investigate the tradeoff effect between the isotropic and anisotropic parameters. In both these cases noise was left out to consider the pure tradeoff effect. The "SYN HOR2" and "SYN_HOR3" models (third and fourth columns in Figure 12) represent purely anisotropic and isotropic cases, respectively. For these two cases the inversion parameters were identical. For the anisotropic model, the isotropic component is negligibly small. For the isotropic model the anisotropy in most parts of the study area is less than $1 \%$. Some small anisotropy artifacts are observed around the central "red" anomaly. However, the reconstructions of these two models show that the algorithm is able to find the correct nature of time residuals and provide stable results for both these cases.

[55] In all previous tests we investigated horizontal resolution using unlimited prisms having the same shapes in all depths. To study the vertical resolution, we have performed a series of tests with vertical anomalies. In Figure 13 we present several 

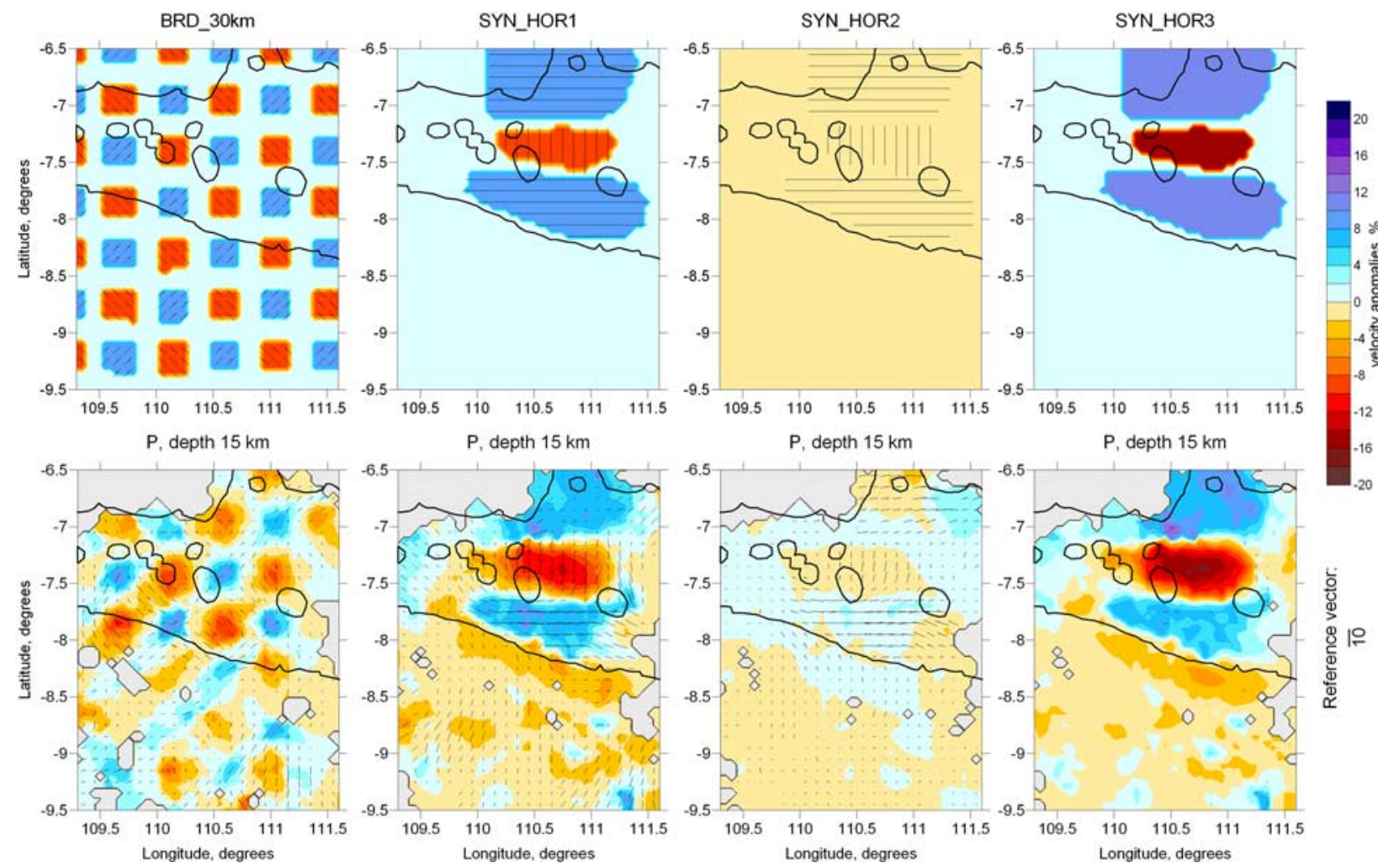

Figure 12. Examples of performing different synthetic tests. (top) The initial models. The parameters for the initial synthetic models are given in Table 2. In all cases the anomalies are defined as unlimited vertical prisms. (bottom) The results for $P$ anomaly reconstructions. Examples for $15 \mathrm{~km}$ depth are shown here only. The indications of isotropic and anisotropic parameters are the same as in Figure 7.

checkerboard tests with anomalies defined across the vertical section. The vertical resolution provided by our observation system is poorer than the horizontal resolution. However, some important patterns can be resolved robustly. The best resolution is observed for the upper part down to $30 \mathrm{~km}$. For the interval of horizontal distance from 190 to $350 \mathrm{~km}$, which correspond to the onshore part, the isotropic patterns are generally reconstructed in the right places. The anisotropy bars tend to be oriented vertically in the low-velocity patterns and horizontally in high-velocity pattern, as defined in the synthetic models. For model 1, the interface at $20 \mathrm{~km}$ depth is clearly seen for the same lateral interval. For the other models the location of the main patterns is reconstructed correctly. However, neither the amplitudes of these anomalies nor their shapes are resolved properly due to strong smearing. For example, if we have two separate bodies of the same anomaly sign at different depths, after inversion they would be probably joined and seen in tomograms as a unit continuous pattern.

[56] In the conditions of poorer vertical resolution a serious question arises about reliability of anoma- lies observed in the mantle. To answer this question, in Figure 14 we present two examples which model the real situation observed along section 1 (Figure 8). The shapes of the synthetic anomalies are shown in Figure 14. The anomalies are presented as prisms which have the same shapes across section 1. Thickness of prisms for all anomalies is $200 \mathrm{~km}$. In this model we defined anisotropic $P$ and isotropic $S$ velocity anomalies. One of the purposes of the presented test is to check, whether the inclined low-velocity anomaly beneath the MLA is real or the results of smearing of a strong crustal anomaly. Note that the purpose of this test is not in showing the absence of smearing. Obviously, vertical smearing caused by sources/receivers configuration takes place in all the reconstructed models. How it is possible to understand whether the anomaly we observe in the mantle is an artifact due to smearing of crustal anomalies or if it is generated by real mantle structures? To answer this question, we propose two models which represent these two hypotheses. Comparing their reconstructions shows which of 

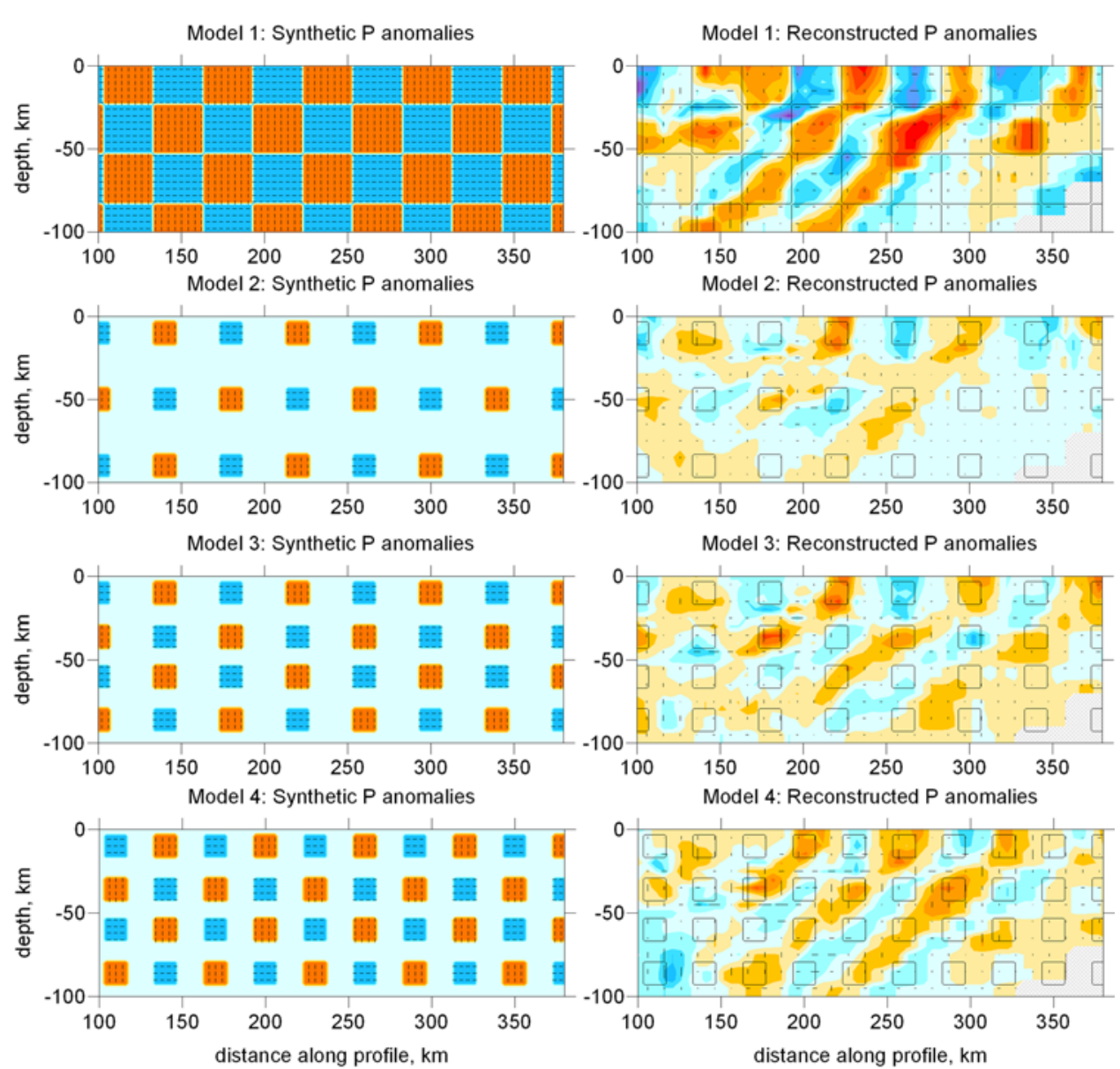

Reference Vector, \%:

6

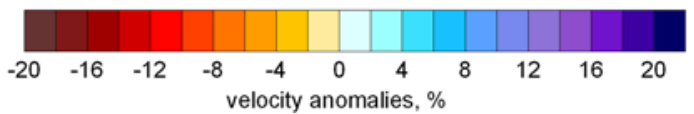

Figure 13. Examples of performing different synthetic tests for checking vertical resolution. (left) The initial models. In all cases the anomalies are defined as unlimited horizontal prisms. (right) The results for $P$ anomaly reconstructions. In the plots with reconstructed anomalies, the positions of the initial patterns are highlighted. The indications of isotropic and anisotropic parameters are the same as in Figure 8.

them is more probable for the real Earth. We see that the reconstruction in case of model 2 with only crustal anomalies is not similar to the observed model (Figure 8). In the highlighted area in the mantle, the reconstructed structure remains almost homogeneous for both $P$ and $S$ models. Thus, we conclude that the vertical smearing of crustal anomalies is not as strong as it could be. On the contrary, reconstruction for the model 1 (left column) in the case of $P$ data is quite similar to the observed $P$ anomalies in Figure 8 . For the $S$ model the reconstruction of the mantle keel is not as clear as for the $P$ model. However, the reconstruction result of the $S$ velocity anomalies is also similar to the observed $S$ model in Figure 8. On the basis of these results, we claim that the model with the mantle keel (model 1 in Figure 14) seems to be more realistic to explain the real observations.

[57] Another problem is that in our results, the slab is not marked by any velocity anomalies. At the same time, in other subduction areas, such as central Chile [Koulakov et al., 2006] and others, application of the same algorithm revealed clear images of high-velocity slabs. Evidences for highvelocity slab beneath Java follow from different tomographic studies based on global data sets [e.g., Bijwaard et al., 1998; Gorbatov and Kennett, 2003]. Absence of clear slab images in our local earthquake tomographic inversion might be explained by insufficient ray coverage. The deep events are located in the upper part of the slab, and only small part of the raypaths from these events 

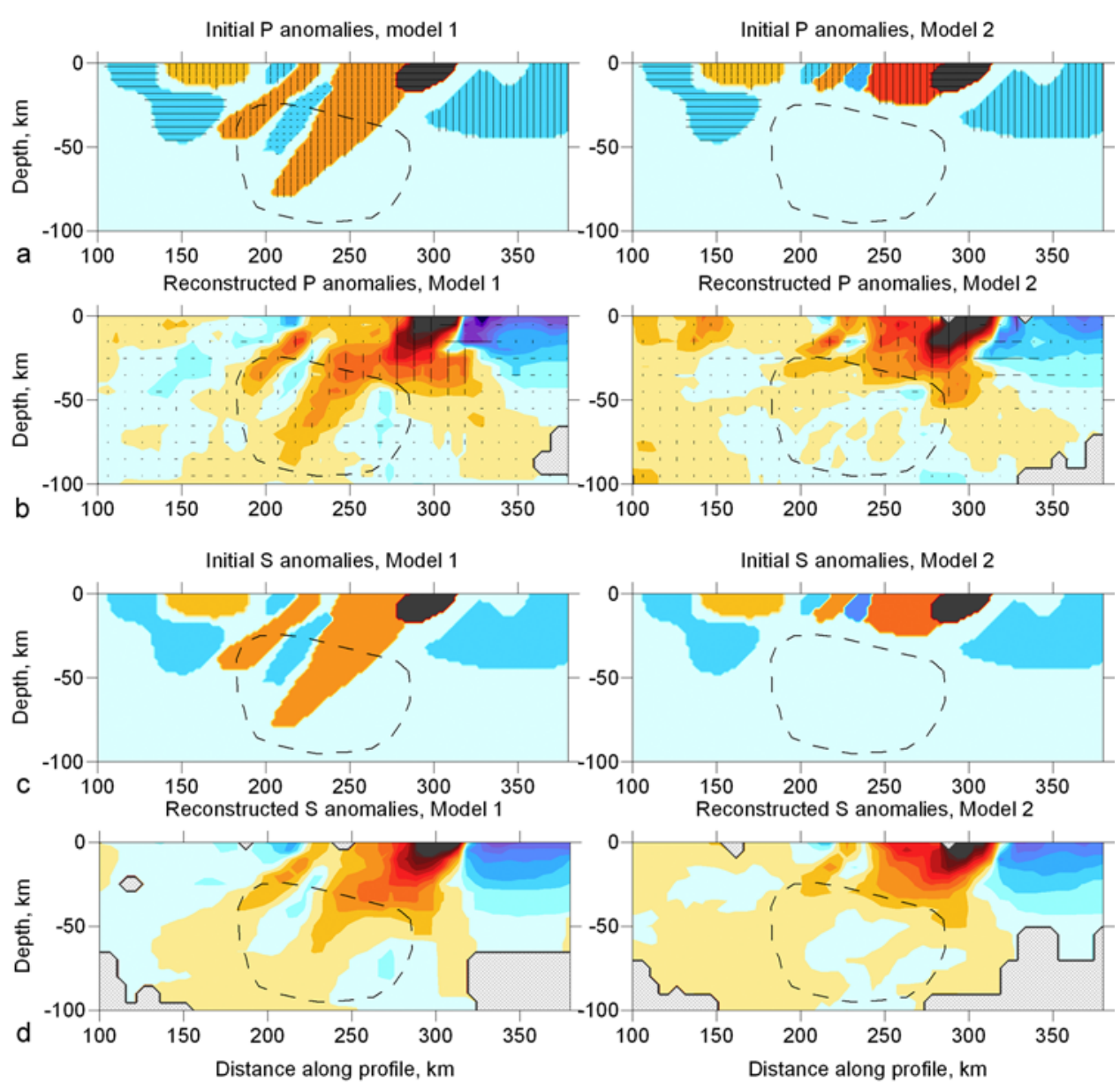

Reference Vector, \%:

$\overline{6}$

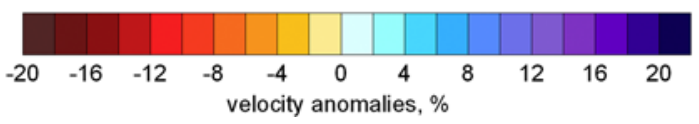

Figure 14. Reconstruction of two synthetic models defined in vertical section 1, the same as in Figure 8. (left) Model 1 represents real situation; (right) model 2 contains mostly the anomalies in the crust. (a and b) Anisotropic $P$ and (c and d) isotropic $S$ models are presented. Indications for anisotropy are the same as in Figure 7. The dotted line indicates the key area where the difference between two models is most important.

travel inside the slab. Furthermore, for the deep events there is tradeoff between source depth, origin time, and velocity which prevents obtaining correct velocity values. We have checked the capacity of the algorithm to reveal the presence of high-velocity slab, at least at a qualitative level. In Figure 15 we present results of synthetic reconstruction for three different models. We considered three models: without slab (Figure 15, top), with high-velocity slab (Figure 15, middle), and high velocity slab with low-velocity crust (Figure 15, bottom). All these cases are distinguished at a qualitative level. It means that if the real structure of the slab was similar to cases presented in Figure 15 (middle) and Figure 15 (bottom), we would see some signature of the high-velocity slab. Absence of such signature in real results presumes that there is another explanation than insufficient resolution. It could be either thicker oceanic crust or lower than expected slab velocity in the uppermost $100 \mathrm{~km}$ depth. However, local earthquake data are not optimal to check these hypotheses.

\section{Discussion}

\subsection{New Features in the Isotropic Results}

[58] Isotropic features obtained for the same region have already been discussed in our previous paper [Koulakov et al., 2007]. The isotropic model obtained in this study is not considerably different compared to the previous ones. However, updating the data set with new traveltimes and more accurate data selection allowed us to reveal some new 

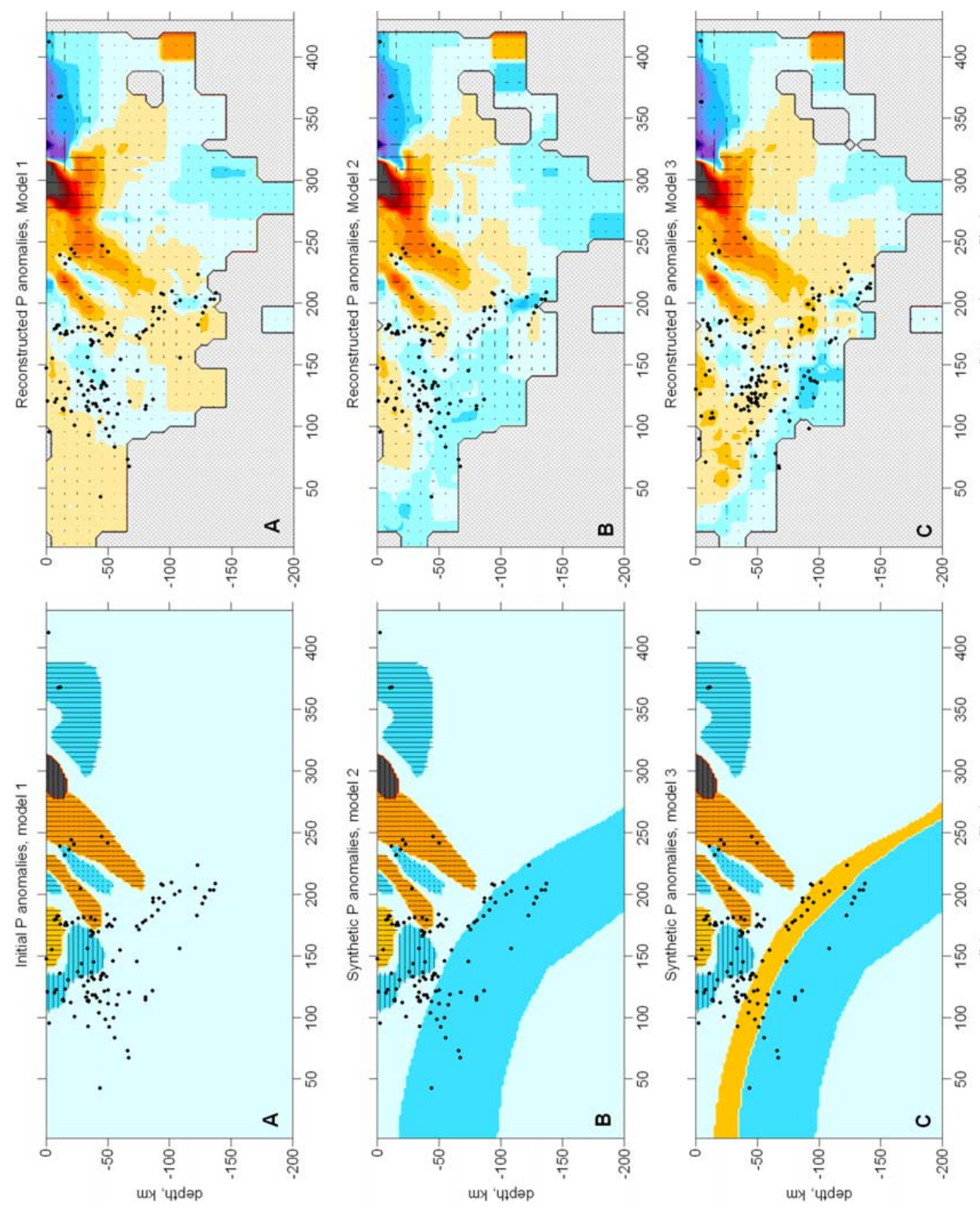

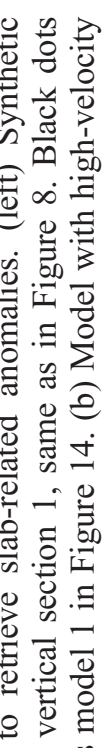

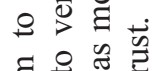

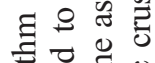

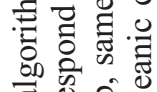

สิ

$\Xi$ 过

फั응 응

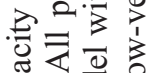

엉

吅苛 寻

뭉

क 을 능

吾

छ

苍焉

을.

क

ம $\dot{0}$ 苟

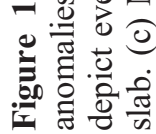




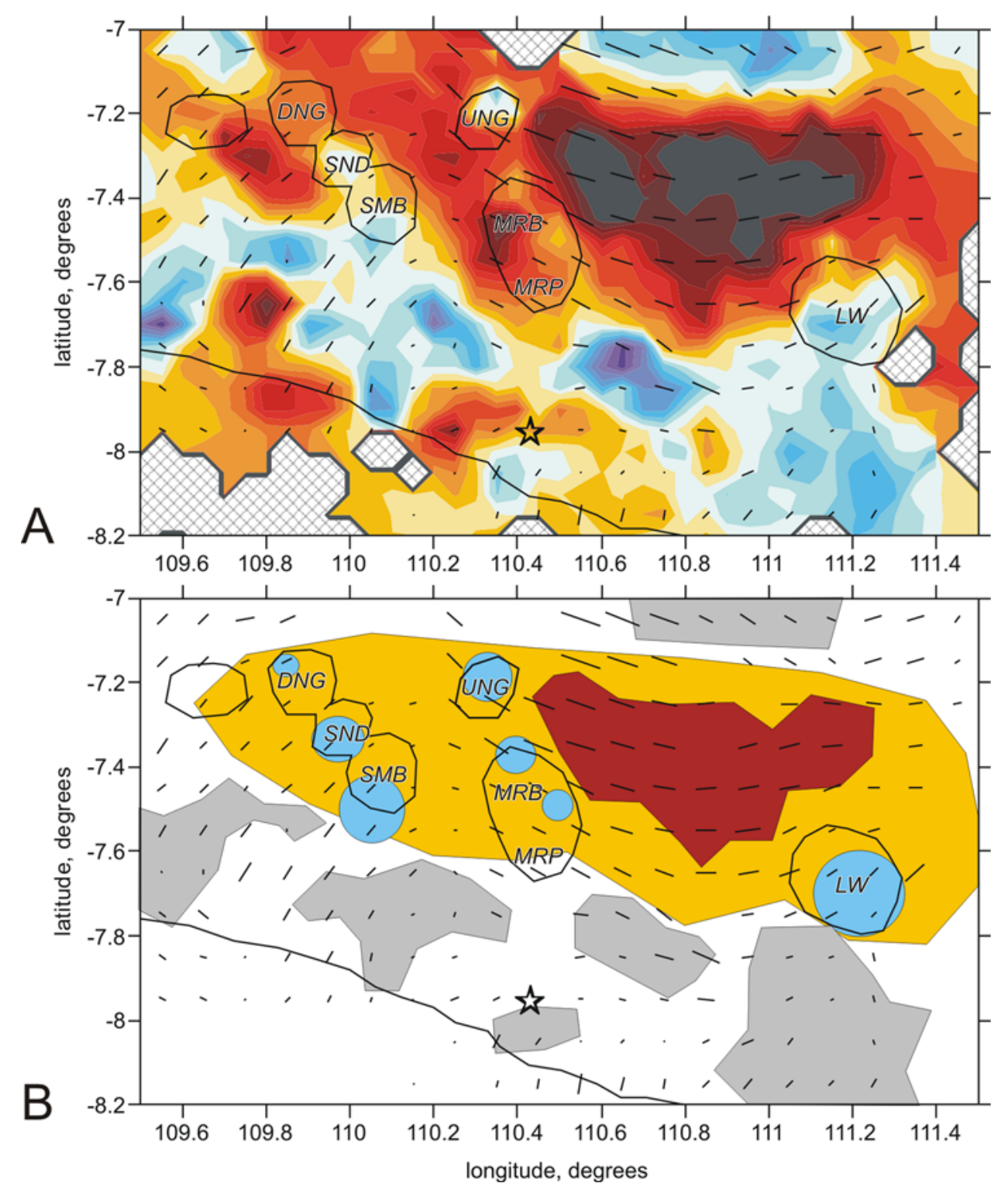

Figure 16. Interpretation of the isotropic and anisotropic anomalies in the uppermost crust. (a) Zoomed map of the resulting model at the depth of $5 \mathrm{~km}$, same as shown in Figure 7. Star indicates the position of the Bantul $M_{\mathrm{w}}=6.5$ earthquake (26 May 2006 UTC). (b) Some highlighted structures mentioned in the interpretation. The dark red area is the MLA anomaly with an extremely strong amplitude. The yellow area is supposed as feeding the volcanoes in central Java. Blue circles are placed over locally higher-velocity anomalies. They probably reflect the position of magmatic intrusions frozen in volcanic channels and reservoirs. Grey areas are placed over the high-velocity anomalies in the forearc and probably mean rigid crustal blocks surrounded by folded belts.

features in our model. Furthermore, taking into account new results of anisotropy we were able to look at the isotropic results from another point of view and to propose new interpretation for the features which were known before.

[59] In Figure 16 we present our interpretation of the results obtained for the shallowest layer. The most prominent feature at $5 \mathrm{~km}$ depths is a series of very strong low-velocity anomalies beneath the middle part of central Java. They appear to be located between the main volcanic complexes. The strongest anomaly is MLA located between the Lawu and Merapi complexes (MER-MRB-UNG) and indicated in Figure 16 with dark red. This study confirms very strong amplitude of this anomaly, about $-30 \%$. Another anomaly is located between the Sumbing and Merapi complexes, and the smallest anomaly is detected between the Sumbing and Slamet volcanoes. We believe that 
all these anomalies are part of one general anomaly indicated in Figure 16 as yellow area. This anomaly is separated by local high-velocity anomalies (blue circles) which are apparently associated with the volcanoes. It is possible that these anomalies represent the location of channels or chambers filled with frozen magmatic rocks having higher seismic velocities. This hypothesis is supported by the fact that the strongest high-velocity patterns are observed beneath dormant volcanoes (e.g., Lawu, Sumbing, Sundoro, Merbabu, Ungaran). Beneath Merapi, the most active volcano in this region, such a feature is manifested less clearly.

[60] In the forearc, between the coast and the volcanoes, the isotropic velocity structure is strongly heterogeneous. We believe that high-velocity regions alternated with low-velocity anomalies represent rigid crustal blocks separated by folded areas. Unfortunately, the forearc area is covered by thick layer of volcanic products and sediments, and we cannot use robust geological information to corroborate or disprove our assumption about configuration of crustal blocks.

[61] In the vertical sections (Figure 8) we observe an interesting combination of seismic velocity anomalies, anisotropy and seismicity distribution. In Figure 17 we present our qualitative understanding of the link between these observations and the manifestation of surface tectonics and volcanism. We can see an inclined low-velocity anomaly which links the seismicity cluster at $110-130 \mathrm{~km}$ depth with the MLA. We suppose that this anomaly is related to migration of fluids ascending from the subducted slab. The seismicity cluster at a depth of $\sim 120 \mathrm{~km}$, marked by a pink ellipse in Figure 17, can be explained by phase transitions in the oceanic crust, which cause significant fluids release [e.g., Poli and Schmidt, 1995]. These fluids move upward (blue drops in Figure 17), and decrease the melting temperature in the overlying mantle and crust. This might cause ascent of diapirs (dark red drops) which reach the Earth surface and cause the origin of volcanism. The natural question is why fluid migration does not occur vertically but along an inclined zone with an angle of about $45^{\circ}$. Actually, in the mantle wedge, there coexist several different processes (mechanical ascend due to Archimedes forces, corner flow, melting, and chemical reactions). Summary effect of such multicomponent system is hardly predictable. One of the possible explanations can be an effect of drift by corner flow in the mantle wedge which is illustrated with a simplified scheme in Figure 18.
Indeed, when the fluids are released from the slab at $120 \mathrm{~km}$ depth [e.g., Poli and Schmidt, 1995] they start migrating upward with a velocity $V_{\text {fluid }}$. However, inside the coupling zone driven by the subducted slab, these fluids are drifted right and down along the subduction. In the upper half of the wedge the drift will develop to another direction due to trenchward corner flow. If vertical velocity $V_{\text {fluid }}$ remains constant, the summary horizontal drift of fluids will be not zero, and the fluids will move to the surface at larger distance from the trench. In this case, the value of the summary horizontal drift depends on velocity of rising of fluids, its evolution inside the mantle wedge, and velocity of subduction. The problem of this explanation is that in this case the path of fluid migration should have strong curvature, while in the tomography results, fluid related anomaly seems to be straight. On the other hand, the vertical resolution in the mantle is rather poor. Obtaining a more detailed shape of this anomaly (i.e., if it is bended or not) is obviously a problem which cannot be solved with the existing data set.

[62] In vertical section at shallower depths we observe another low-velocity anomaly, which seems to be parallel to the mentioned MLA related anomaly. It can be seen that significant amount of seismic events (indicated by the blue ellipse in Figure 17) occur in this zone. Another seismicity cluster is located just above the slab and is indicated by a green ellipse. Both these clusters surround a high-velocity aseismic zone which probably indicates a rigid block in the forearc. A similar V-shaped structure above the subduction due to compression has been demonstrated in results of numerical modeling for the case of central Andes by Babeyko and Sobolev [2005]. We suppose that in central Java the asperity effect in the slab may also cause compression in the overlaying plate and produce $\mathrm{V}$-shaped thrusting in a similar way as in central Andes.

[63] It is interesting to note that a similar geodynamical situation is observed in the central Andes. Results of velocity and attenuation tomography [Koulakov et al., 2006; Schurr et al., 2003] reveal very similar inclined low-velocity zones which link a seismicity cluster at $120 \mathrm{~km}$ depth in the slab with the volcanic arc. Just behind the arc, beneath Altiplano, strong low velocities and high attenuation is observed. Other evidence for existence of low-velocity layers beneath Altiplano are revealed from receiver function [Yuan et al., 2000] and active seismic studies [Yoon et al., 

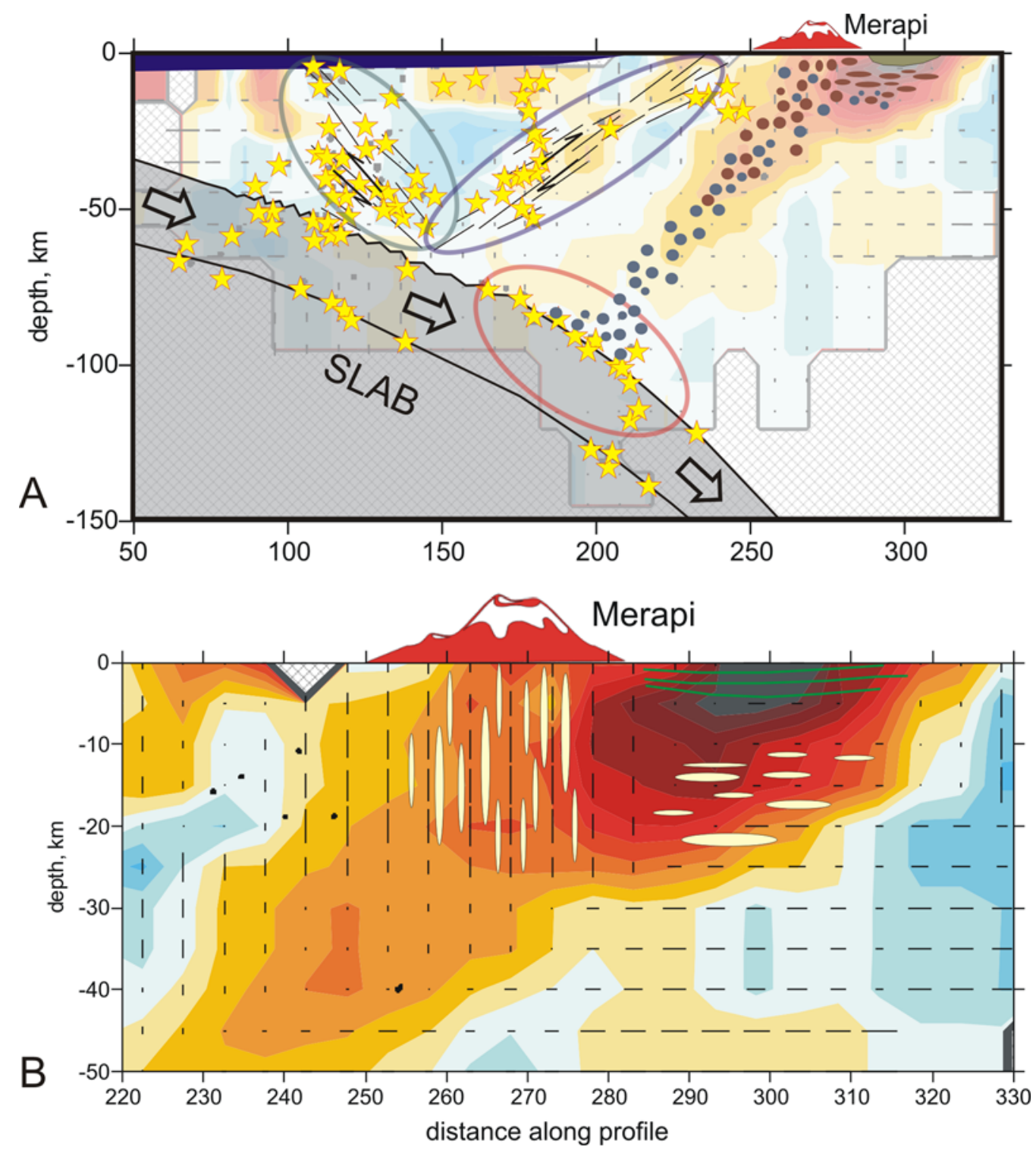

Figure 17. (a) Interpretation of the results. The background is the result for $P$ velocities in section 1, the same as in Figure 8. Yellow stars show distribution of local seismicity recorded within this study. The pink ellipse highlights the events in the slab at $110-130 \mathrm{~km}$ depth which could be related to phase transition and fluid release from the slab. Small blue and dark red circles indicate schematic distribution of released fluids and partial melting zones, respectively, according to our interpretation. Blue and green ellipses highlight the events which could be related to thrusting caused by increasing of the friction rate on the slab upper surface. Shallow green area to the right of Merapi indicates the sediment cover above the MLA. Black strokes above the slab indicate possible areas with maximum stress concentration. (b) Zoom for the area beneath Merapi volcano. Elongated ellipses show schematically distribution of channels, dykes, and lenses filled with magmatic material. Green lines indicate schematically sediment layers.

2003]. We suppose that the accumulation of diapirs in the MLA and beneath the Altiplano have a similar nature.

\subsection{Discussion of the Anisotropy Results}

[64] The mechanisms which are used to explain anisotropy in the crust and the mantle are usually classified in two main groups: shape-preferred orientation (SPO) and lattice-preferred orientation (LPO) of Earth materials [e.g., Fouch and Rondenay, 2006]. Seismic anisotropy resulting from SPO is due to structural features of contrasted patterns (each of them is possibly isotropic) that provide a preferential fast and slow direction of seismic wave 


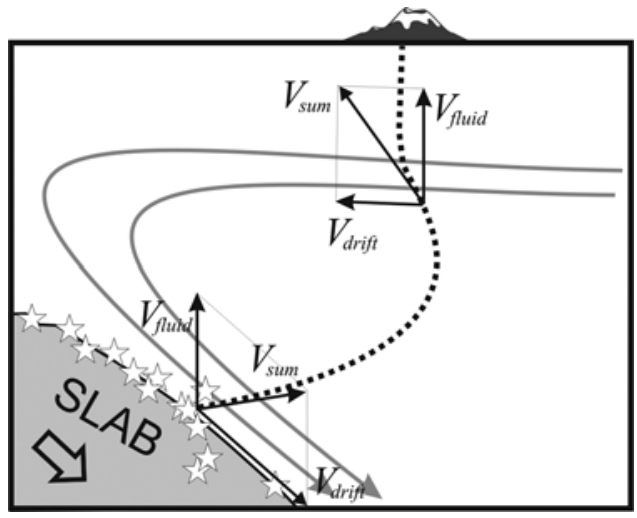

Figure 18. Scheme illustrating the fluid drift in the corner flow.

propagation. In the crust SPO can be related to faults, regularly oriented cracks, layering, and other structural patterns [e.g., Bokelmann, 1995]. In the mantle SPO may be generated by melt-filled fissures or lenses or compositional lamellae [e.g., Zimmerman et al., 1999]. The fast polarization direction from SPO occurs along the long axis or plane of structures and the degree of anisotropy is proportional to the magnitude of velocity contrasts. Anisotropy caused by lattice preferred orientation (LPO) of crystallographic axes of elastically anisotropic minerals takes place both in the crust and in the mantle. In the crust LPO anisotropy is often caused by biotite and hornblende. In the upper mantle, seismic anisotropy is usually generated by olivine [e.g., Karato and Wu, 1993; Ben-Ismail and Mainprice, 1998], and orthopyroxene [e.g., Ben-Ismail et al., 2001]. As follows from numerical modeling [e.g., McKenzie, 1979; Ribe, 1989] and physical experiments [e.g., Karato, 1987; Zhang and Karato, 1995] under relatively dry conditions, olivine $a$ axis (the seismically fast direction) align roughly parallel to the direction of maximum extension or is controlled by the flow direction. Experimental results have also shown that water plays a critical role in modifying mantle velocities and LPO development [e.g., Jung and Karato, 2001].

[65] Our results show that crust and upper mantle beneath central Java appear to be strongly anisotropic. We suppose that both SPO and LPO are responsible for the anisotropy effect. From the synthetic tests we can conclude that robust reconstruction of anisotropic parameters is only observed in the onshore part of the study area. Our main results show magnitudes of anisotropy of up to $8-10 \%$. However, we admit that these values should be interpreted with prudence. We have already discussed in section 4 that stronger damp- ing causes considerable decrease of the amplitude without significant worsening of the data fit.

\subsubsection{Anisotropy in the Forearc}

[66] In the crust beneath central Java we observe clear separation of different anisotropic regimes (Figure 16). In the forearc between the southern coast of Java and the volcano chain the anisotropic properties seem to be chaotic and relatively weak: all directions of fast velocities coexist within this relatively small area. Variety of anisotropy orientations is a clear indicator to complex crustal structure in the forearc. This is also supported by mosaic structure of isotropic velocity anomalies. Low amplitude of anisotropy in the forearc can be explained by insufficient resolution. As the checkerboard test shows, the tomographic inversion cannot map brutal changes of anisotropy in separate blocks if their size is small. We suppose that the anisotropy in the forearc can be associated with a structure of crustal blocks and fault zones between blocks. Inside a separate block the anisotropy possibly records fossil traces of past tectonic processes. Further rotation of these blocks due to tectonic displacements causes rotation of anisotropy. The Bantul $\mathrm{M}_{\mathrm{w}}=6.5$ earthquake (26.05.2006 UTC) with strike-slip mechanism is one of the evidences for active horizontal displacements in the forearc.

\subsubsection{Anisotropy in the Volcanic Area and MLA}

[67] The strongest horizontal anisotropy in the crust is observed within a large low-velocity anomaly between Merapi and Lawu volcanoes (MLA). Inside this anomaly we observe an east-west trending of faster velocities and the amplitude of anisotropy reaches $10 \%$. In the vertical section (Figure 17b) we observe clear separation according to character of the vertical anisotropy. Although synthetic tests show poorer resolution for vertical anisotropy parameters, at a qualitative level, some important features can be singled out robustly. Beneath the volcanoes, in the southern part of MLA, faster vertical velocities are observed, while in the northern part, where maximal amplitudes of velocity anomalies were found $(30-35 \%)$, the anisotropy tends to be horizontal. The nature of such strong velocity anomaly and anisotropy in the MLA is still under debate.

[68] For the volcanic areas, we suppose that fast vertical velocities and arc parallel trending of horizontal anisotropy can be caused by existence 
of vertical dykes and channels beneath the volcanoes. Most of them are filled with higher-velocity material of frozen magma. Some of them are observed beneath the volcanoes (blue circles in Figure 16b), but the characteristic size of most patterns is usually smaller than the resolution capacity of the tomographic algorithm and they are not detectable in the tomograms. However, such structure with elongated vertical fine features causes higher effective velocity in vertical direction which is detected in the anisotropic results.

[69] Horizontal trending of anisotropy in the northern part of the MLA which is seen in the vertical section (Figure 17b) is probably due to layering of sediments in the uppermost part. Additionally, we suppose that it may be also due to penetration of horizontally oriented intrusions. Very low velocities in MLA and strong attenuation of $S$ velocities are possible indicators that these intrusions are filled with molten magma. Another indirect argument for this hypothesis is large level of remnant residuals for the stations located within MLA. These unexplained residuals can be due to small high contrasted patterns (magma pockets) which are below the resolution capability of the inversion algorithm, but still affect the traveltimes. As for strong anisotropy in MLA observed in the map view, we believe that it can be due to LPO fabrics at a micro level which is controlled by the regional stress regime. Alternative mechanisms, related to macro structures (e.g., trench parallel faults) seem to us improbable there. Together with trench parallel anisotropy in the map view, they would occur as a vertical anisotropy in the cross section, which is not actually observed. We suppose that east-west trending of horizontal anisotropy in MLA is related to the regional stress regime. Deviatoric stresses induce preferential opening and closing of cracks, potentially introducing seismic anisotropy in rocks. These effects are especially evident in cracked porous media [Gibson and Toksoz, 1990] as expected in MLA, where a lot of thermal fields are observed. In the case of compressional stress, fast velocities are observed parallel to compressional stress direction [e.g., Lees and Wu, 1999]. On the contrary, extension regime causes the anisotropy with fast velocity direction perpendicular to the orientation of extension [e.g., Audoine et al., 2004]. Thus, dominant E-W orientation of fast velocity within the MLA might be evidence that significant extension along the north-south direction and/or compression in the E-W direction takes place in this area. This might be an initial stage of the back-arc extension which is actively discussed in the literature for different subduction zones (e.g., see overview in the work of Mantovani et al. [2001]) Based on physical modeling, Boutelier et al. [2003] have shown that extensional processes in the arc and backarc areas are controlled by thickness and composition of the crust. In central Java, the structure of the subduction complex seems to be corresponding to the case when the maximal extension is expected in the backarc which correspond to MLA. Extension in the arc area might be also related with volcanic processes [e.g., Guffanti et al., 1990]. Thick sediment basin within the MLA is probably another indirect evidence for regional extension. Unfortunately, for central Java, we do not know any other studies which provide any information about deformation regime, such as detailed GPS measurements or focal mechanisms calculation, which could corroborate or disprove this statement.

\subsubsection{Upper Mantle}

[70] For the deeper section, the horizontal orientation of fastest velocity axes seems to be fairly regular. At a depth of $25 \mathrm{~km}$ and deeper, which corresponds to the mantle, the anisotropy beneath the coastal area is oriented trench parallel and roughly perpendicular to the direction of subduction.

[71] Numerous results of SKS splitting and seismic tomography, which provide anisotropy distribution in the crust and upper mantle are presently available for different subduction zones. In some areas the anisotropy distribution is quite complex. For example, in some parts of Japan [e.g., Ishise and Oda, 2005], Isu-Bonin arc [Anglin and Fouch, 2005], and beneath Marianna system [e.g., Pozgay et al., 2007] the anisotropy orientation vary in a large diapason of angles, from arc parallel to arc perpendicular.

[72] However, in most cases the anisotropy results show similar trench parallel orientation of fast velocities in the mantle wedge (see overview in the work of Fouch and Fischer [1996]). For example, trench parallel anisotropy is observed beneath New Zealand [e.g., Audoine et al., 2004], the Aleutian-Alaska [e.g., Yang et al., 1995], CostaRica and Nicaragua [Abt and Fischer, 2008; Dinc et al., 2009], Ryukyu arc [Long and Van der Hilst, 2006], Kamchatka [Levin et al., 2004] and other subduction zones.

[73] To explain the trench parallel flows in the mantle wedge there are at least two alternative 
concepts. The first one presumes trench parallel flow in the mantle wedge. In this case, the anisotropy is related to the fast symmetry axis of olivine which is parallel to the flow direction (i.e., A-type dislocation creep, as in the work of Zhang and Karato [1995]). For example, in Chile-Argentina subduction zone trench parallel anisotropy is explained by trench parallel flows in the mantle wedge caused by variable steepness of the slab [e.g., Russo and Silver, 1994; Anderson et al., 2004; Kneller and van Kekken, 2007]. For the Costa-Rica and Nicaragua regions, Hoernle et al. [2008] found geochemical evidences of trench parallel flows in the mantle wedge which is supported by seismological observations. In the Marianna subduction system, similar mechanisms of trench parallel flows are presumed by Kneller and van Keken [2007].

[74] Alternatively, Jung and Karato [2001] suggest that trench-parallel fast directions near subduction zones may be caused not by trench-parallel flow, but instead by the expected slab entrained corner flow with unusual olivine orientations due to a high $\mathrm{H}_{2} \mathrm{O}$ content. One of them is a fabric called type B for which the $\mathrm{c}$ axis is parallel to the shear direction and the (010) plane is subparallel to the shear plane. Similar fabrics may also develop in the presence of melt [Holtzman et al., 2003]. In a setting where the shear direction (direction of flow) is trench-perpendicular, fabric B could explain the presence of trench-parallel anisotropy.

[75] Our results for central Java seem to be in good agreement with the later concept which explains the trench-parallel anisotropy in the mantle wedge by presence of B-type olivine. This fabric is generated in special conditions which presume presence of water and melts. Our tomographic results show an inclined low-velocity anomaly which connects the seismicity cluster at the depth of about $100 \mathrm{~km}$ with the active volcanoes on the surface (Figure 17). We interpret this anomaly as path of fluids which are released from the slab due to phase transitions. These fluids may initiate active melting in the mantle wedge and in the crust beneath the volcanoes. Both fluids and melts may take part at producing B-type olivine with orientation of the fast axis perpendicular to the flow direction.

[76] The main conclusions of this study are following:

[77] 1. The anisotropic inversion in central Java significantly improves the data fit, in comparison to the isotropic model $(0.177 \mathrm{~s}$ and $0.227 \mathrm{~s} \mathrm{RMS}$, respectively). In this area, the anisotropy value (the difference between fast and slow horizontal velocities) reaches $10 \%$.

[78] 2. The anisotropic parameters are much more sensitive to the data distribution than the isotropic perturbations. The tests performed in this study show that in marginal areas the anisotropy reconstruction is not stable. A stable solution for anisotropy is obtained only for the crust beneath central and southern onshore parts of Java. Computing reliable results for anisotropic parameters requires much better data coverage and quality than for the isotropic model.

[79] 3. In the forearc (area between southern coast and volcanoes), the structure of both isotropic and anisotropic structure is strongly heterogeneous. Variety of anisotropy orientations and highly contrasted velocity patterns can be explained by complex block structure of the crust.

[80] 4. Beneath volcanoes we observe faster velocities in vertical direction. Probably, this is an indicator for vertically oriented structures (channels, dykes).

[81] 5. In the crust beneath the middle part of central Java, north to Merapi and Lawu volcanoes, we observe a large and very intense anomaly with a velocity decrease of up to $30 \%$ and $35 \%$ for $P$ and $S$ models, respectively. Inside this anomaly E-W orientation of fast velocity takes place that is probably caused by regional extension stress regime. In vertical section beneath this anomaly we observe faster horizontal velocities that might be explained by layering of sediments and/or penetration of quasi-horizontal lenses with molten magma.

[82] 6. In the mantle, trench parallel anisotropy is observed throughout the study area. Such anisotropy in the slab entrained corner flow can be due to presence of B-type olivine having predominant axis parallel to the shear direction [Jung and Karato, 2001], which appears in conditions of high water or/and melting content.

[83] 7. The crustal seismicity in the forearc seems to be located within a V-shaped zone which could be related to a compressive regime in the lithosphere caused by high asperity in the slab.

[84] 8. Just beneath Lawu Mount we observe a cluster of crustal seismicity, which seems intriguing because this volcano is considered dormant. 
[85] 9. In this paper we present a new code for anisotropic inversion of local earthquake data, ANITA, which possesses a wide range of possibilities for testing the derived results. This code is freely available through personal communication with the first author (koulakoviy@ipgg.nsc.ru), and we encourage its use for processing different data sets in other areas.

\section{Acknowledgments}

[86] This research was founded by the Federal Ministry of Education and Research (BMBF) within the special program GEOTECHNOLOGIEN, and the GeoForschungsZentrum Potsdam (GFZ). This study is supported by Russian Foundation for Basic Researches (08-05-00276-a), Heimholtz Society and RFBR joint research project 09-05-91321-SIG_a, multidisciplinary projects SB RAS 21 and SB-UrO-DVO RAS 96, and project ONZ RAS 7.4. Instruments used for data collection were provided by the Geophysical Instrument Pool Potsdam (GIPP), the Christian Albrecht Universität, Kiel, and the IFM-GEOMAR, Kiel. We are grateful to Associate Editor and two anonymous reviewers which provided very hard but constructive criticism that allowed us to significantly improve this study. Special thanks to Amerika Manzanares for help with picking the data and editing the text of the paper.

\section{References}

Abt, D. L., and K. M. Fischer (2008), Resolving three-dimensional anisotropic structure with shear-wave splitting tomography, Geophys. J. Int., 173, 859-886, doi:10.1111/j.1365-246X. 2008.03757.x.

Anderson, M. L., G. Zand, E. Triep, M. Fouch, and S. Beck (2004), Anisotropy and mantle flow in the Chile-Argentina subduction zone from shear wave splitting analysis, Geophys. Res. Lett., 31, L23608, doi:10.1029/2004GL020906.

Anglin, D. K., and M. J. Fouch (2005), Seismic anisotropy in the Izu-Bonin subduction system, Geophys. Res. Lett., 32, L09307, doi:10.1029/2005GL022714.

Audoine, E., M. K. Savage, and K. Gledhill (2004), Anisotropic structure under a back arc spreading region, the Taupo Volcanic Zone, New Zealand, J. Geophys. Res., 109, B11305, doi:10.1029/2003JB002932.

Babeyko, A. Y., and S. V. Sobolev (2005), Quantifying different modes of the Late Cenozoic shortening in the central Andes, Geology, 33, 621-624, doi:10.1130/G21126.1.

Backus, G. E. (1965), Possible forms of seismic anisotropy of the uppermost mantle under oceans, J. Geophys. Res., 70, 3429-3439, doi:10.1029/JZ070i014p03429.

Ben-Ismail, W., and D. Mainprice (1998), An olivine fabric database: An overview of upper mantle fabrics and seismic anisotropy, Tectonophysics, 296(1-2), 145-157, doi:10.1016/ S0040-1951(98)00141-3.

Ben-Ismail, W., G. Barruol, and D. Mainprice (2001), The Kaapvaal craton seismic anisotropy: Petrophysical analyses of upper mantle kimberlite nodules, Geophys. Res. Lett., 28(13), 2497-2500, doi:10.1029/2000GL012419.

Bijwaard, H., W. Spakman, and R. Engdahl (1998), Closing the gap between regional and global travel time tomography, J. Geophys. Res., 103, 30,055-30,078, doi:10.1029/ 98JB02467.
Bokelmann, G. H. R. (1995), P wave array polarization analysis and effective anisotropy of the brittle crust, Geophys. J. Int., 120, 145-162, doi:10.1111/j.1365-246X.1995. tb05917.x.

Bokelmann, G. H. R. (2002), Convection-driven motion of the North American craton: Evidence from P wave anisotropy, Geophys. J. Int., 148, 278-287, doi:10.1046/j.1365246X.2002.01614.x.

Boutelier, D., A. Chemenda, and J.-P. Burg (2003), Subduction versus accretion of intra-oceanic volcanic arcs: Insight from thermo-mechanical analogue experiments, Earth Planet. Sci. Lett., 212, 31-45.

Dinc, A. N., I. Koulakov, M. Thorwart, W. Rabbel, E. Flueh, and I. Arroyo (2009), A combined tomographic inversion of two independent amphibious networks in central Costa Rica, Geophys. J. Int., in press.

Draper, N. R., and H. Smith (1966), Applied Regression Analysis, 407 pp., John Wiley, New York.

Eberhart-Phillips, D., and C. M. Henderson (2004), Including anisotropy in 3-D velocity inversion and application to Marlborough, New Zealand, Geophys. J. Int., 156, 237-254, doi:10.1111/j.1365-246X.2003.02044.x.

Farra, V., and I. Psencýk (2008), First-order ray computations of coupled S waves in inhomogeneous weakly anisotropic media, Geophys. J. Int., 173, 979-989, doi:10.1111/j.1365246X.2008.03778.x.

Fouch, M. J., and K. M. Fischer (1996), Mantle anisotropy beneath northwest Pacific subduction zones, J. Geophys. Res., 101, 15,987-16,002, doi:10.1029/96JB00881.

Fouch, M. J., and S. Rondenay (2006), Seismic anisotropy beneath stable continental interiors, Phys. Earth Planet. Inter., 158, 292-320, doi:10.1016/j.pepi.2006.03.024.

Gibson, R. L., and M. N. Toksoz (1990), Permeability estimation from velocity anisotropy in fractured rocks, J. Geophys. Res., 95, 15,643-15,655, doi:10.1029/JB095iB10p15643.

Gorbatov, A., and B. L. N. Kennett (2003), Joint bulk-sound and shear tomography for Western Pacific subduction zones, Earth Planet. Sci. Lett., 210, 527-543, doi:10.1016/S0012821X(03)00165-1.

Guffanti, M., M. A. Clynne, J. G. Smith, L. J. P. Muffler, and T. D. Bullen (1990), Late Cenozoic volcanism, subduction, and extension in the Lassen region of California, southern Cascade Range, J. Geophys. Res., 95(B12), 19,453-19,464, doi:10.1029/JB095iB12p19453.

Hammond, W. C., and D. R. Toomey (2003), Seismic velocity anisotropy and heterogeneity beneath the Mantle Electromagnetic and Tomography Experiment (MELT) region of the East Pacific Rise from analysis of $\mathrm{P}$ and $\mathrm{S}$ body waves, J. Geophys. Res., 108(B4), 2176, doi:10.1029/ 2002JB001789.

Hearn, T. M. (1996), Anisotropic Pn tomography in the western United States, J. Geophys. Res., 101(B4), 8403-8414, doi:10.1029/96JB00114.

Hoernle, K., D. L. Abt, K. M. Fischer, H. Nichols, F. Hauff, G. Abers, P. van den Bogaard, G. Alvarado, M. Protti, and W. Strauch (2008), Geochemical and geophysical evidence for arc-parallel flow in the mantle wedge beneath Costa Rica and Nicaragua, Nature, 451, 1094-1098, doi:10.1038/ nature 06550 .

Holtzman, B. K., D. L. Kohlstedt, M. E. Zimmerman, F. Heidelbach, T. Hiraga, and J. Hustoft (2003), Melt segregation and strain partitioning: Implications for seismic anisotropy and mantle flow, Science, 301, 1227-1230, doi:10.1126/ science. 1087132 .

Ishise, M., and H. Oda (2005), Three-dimensional structure of $P$ wave anisotropy beneath the Tohoku district, northeast Japan, J. Geophys. Res., 110, B07304, doi:10.1029/2004JB003599. 
Iversen, E., and I. Psencýk (2008), Ray tracing and inhomogeneous dynamic ray tracing for anisotropy specified in curvilinear coordinates, Geophys. J. Int., 174, 316-330, doi:10.1111/j.1365-246X.2008.03812.x.

Jung, H., and S. Karato (2001), Water-induced fabric transitions in olivine, Science, 293(5534), 1460-1463, doi:10.1126/science.1062235.

Karato, S. (1987), Seismic anisotropy due to lattice preferred orientation of minerals: Kinematic or dynamic?, in HighPressure Research in Mineral Physics, Geophys. Monogr. Ser., vol. 39, edited by M. H. Manghnani and S. Syono, pp. 455-471, AGU, Washington, D.C.

Karato, S. I., and P. Wu (1993), Rheology of the upper mantle: A synthesis, Science, 260(5109), 771-778, doi:10.1126/ science.260.5109.771.

Kind, R., G. L. Kosarev, L. I. Makeyeva, and L. P. Vinnik (1985), Observations of laterally inhomogeneous anisotropy in the continental lithosphere, Nature, 318(6044), 358-361, doi: $10.1038 / 318358 \mathrm{a} 0$.

Kneller, E. A., and P. E. van Kekken (2007), Trench-parallel flow and seismic anisotropy in the Mariana and Andean subduction systemsNature, 450, 1222-1225, doi:10.1038/ nature06429.

Koulakov, I. (2009), LOTOS code for local earthquake tomographic inversion. Benchmarks for testing tomographic algorithms, Bull. Seismol. Soc. Am., 99(1), 194-214, doi:10.1785/0120080013.

Koulakov, I, and S. V. Sobolev (2006), A tomographic image of Indian lithosphere break-off beneath the Pamir Hindukush Region, Geophys. J. Int., 164, 425-440, doi:10.1111/j.1365246X.2005.02841.x.

Koulakov, I., S. V. Sobolev, and G. Asch (2006), $P$ - and $S$ velocity images of the lithosphere-asthenosphere system in the central Andes from local-source tomographic inversion, Geophys. J. Int., 167, 106-126, doi:10.1111/j.1365246X.2006.02949.x.

Koulakov, I., et al. (2007), $P$ and $S$ velocity structure of the crust and the upper mantle beneath central Java from local tomography inversion, J. Geophys. Res., 112, B08310, doi:10.1029/2006JB004712.

Lees, J. M., and H. Wu (1999), $P$ wave anisotropy, stress, and crack distribution at Coso geothermal field, California, $J$. Geophys. Res., 104, 17,955-17,973.

Levin, V., D. Droznin, J. Park, and E. Gordeev (2004), Detailed mapping of seismic anisotropy with local shear waves in southeastern Kamchatka, Geophys. J. Int., 158, 10091023, doi:10.1111/j.1365-246X.2004.02352.x.

Liang, C., X. Song, and J. Huang (2004), Tomographic inversion of $P n$ travel times in China, J. Geophys. Res., 109, B11304, doi:10.1029/2003JB002789.

Long, M. D., and R. D. Van Der Hilst (2006), Shear wave splitting from local events beneath the Ryukyu arc: Trench-parallel anisotropy in the mantle wedge, Phys Earth Planet Inter, 155, 300-312, doi:10.1016/j.pepi.2006.01.003.

Long, M. D., M. V. de Hoop, and R. D. van der Hilst (2008), Wave-equation shear wave splitting tomography, Geophys. J. Int., 172, 311-330, doi:10.1111/j.1365-246X.2007.03632.x.

Mantovani, E., M. Viti, D. Babbucci, C. Tamburelli, and D. Albarello (2001), Back arc extension: Which driving mechanism?, J. Virtual Explorer, 3, 17-44, doi:10.3809/ jvirtex.2001.00025.

McKenzie, D. (1979), Finite deformation during fluid flow, Geophys. J. R. Astron. Soc., 58, 687-715.

Paige, C. C., and M. A. Saunders (1982), LSQR: An algorithm for sparse linear equations and sparse least squares, Trans. Math. Software, 8, 43-71, doi:10.1145/355984.355989.
Poli, S., and M. W. Schmidt (1995), H2O transport and release in subduction zones: Experimental constrains on basaltic and andesitic systemsJ. Geophys. Res., 100, 22,299-22,314, doi:10.1029/95JB01570.

Pozgay, S. H., D. A. Wiens, J. A. Conder, H. Shiobara, and H. Sugioka (2007), Complex mantle flow in the Mariana subduction system: Evidence from shear wave splitting, Geophys. J. Int., 170, 371-386, doi:10.1111/j.1365-246X.2007. 03433.x.

Ribe, N. M. (1989), Seismic anisotropy and mantle flow, J. Geophys. Res., 94, 4213-4223, doi:10.1029/ JB094iB04p04213.

Russo, R. M., and P. G. Silver (1994), Trench-parallel flow beneath the Nazca plate from seismic anisotropy, Science, 263, 1105-1111, doi:10.1126/science.263.5150.1105.

Schurr, B., G. Asch, A. Rietbrock, R. Trumbull, and C. Haberland (2003), Complex patterns of fluid and melt transport in the central Andean subduction zone revealed by attenuation tomography, Earth Planet. Sci. Lett., 215, 105-119, doi:10.1016/ S0012-821X(03)00441-2.

Serrano, I., T. M. Hearn, J. Morales, and F. Torcal (2005), Seismic anisotropy and velocity structure beneath the southern half of the Iberian Peninsula, Phys. Earth Planet. Inter., 150, 317-330, doi:10.1016/j.pepi.2004.12.003.

Song, L.-P., M. Koch, K. Koch, and J. Schlittenhardt (2004), 2-D anisotropic Pn-velocity tomography underneath Germany using regional traveltimes, Geophys. J. Int., 157(2), 645-663, doi:10.1111/j.1365-246X.2004.02171.x.

Um, J., and C. Thurber (1987), A fast algorithm for two-point seismic ray tracing, Bull. Seismol. Soc. Am., 77, 972-986.

van der Hilst, R. D., and E. R. Engdahl (1991), On ISC PP and $p P$ data and their use in delay-time tomography of the Caribbean region, Geophys. J. Int., 106, 169-188, doi:10.1111/ j.1365-246X.1991.tb04610.x.

Van der Sluis, A., and H. A. van der Vorst (1987), Numerical solution of large, sparse linear algebraic systems arising from tomographic problems, in Seismic Tomography, edited by G. Nolet, pp. 49-83, D. Reidel, Dortrecht, Netherlands.

Vinnik, L. P., V. Farra, and B. Romanowicz (1989), Azimuthal anisotropy in the Earth from observations of SKS at GEOSCOPE and NARS broadband stations, Bull. Seismol. Soc. Am., 79(5), 1542-1558.

Wagner, D., I. Koulakov, W. Rabbel, B.-G. Luehr, A. Wittwer, and H. Kopp (2007), Joint inversion of active and passive seismic data in central Java, Geophys. J. Int., 170, 923-932, doi:10.1111/j.1365-246X.2007.03435.x.

Yang, X., K. M. Fischer, and G. Abers (1995), Seismic anisotropy beneath the Shumagin Islands segment of the AleutianAlaska subduction zone, J. Geophys. Res., 100, 18,165-18,177, doi:10.1029/95JB01425.

Yoon, M., S. Buske, S. Lüth, A. Schulze, S. A. Shapiro, M. Stiller, and P. Wigger (2003), Along-strike variations of crustal reflectivity related to the Andean subduction process, Geophys. Res. Lett., 30(4), 1160, doi:10.1029/ 2002 GL015848.

Yuan, X., S. V. Sobolev, and R. Kind (2000), Subduction and collision processes in the central Andes constrained by converted seismic phases, Nature, 408, 958-961, doi:10.1038/ 35050073.

Zhang, S, and S. Karato (1995), Lattice preferred orientation of olivine aggregates deformed in simple shear, Nature, 375, 774-777, doi:10.1038/375774a0.

Zimmerman, M. E., S. Q. Zhang, D. L. Kohlstedt, and S. Karato (1999), Melt distribution in mantle rocks deformed in shear, Geophys. Res. Lett., 26(10), 1505-1508, doi:10.1029/1999GL900259. 